\title{
Distinct Effects of Repeated Restraint Stress on Basolateral Amygdala Neuronal Membrane Properties in Resilient Adolescent and Adult Rats
}

\author{
Andrea Hetzel' and J Amiel Rosenkranz*,' \\ 'Department of Cellular and Molecular Pharmacology, Chicago Medical School, Rosalind Franklin University of Medicine and Science, \\ North Chicago, IL, USA
}

\begin{abstract}
Severe and repeated stress has damaging effects on health, including initiation of depression and anxiety. Stress that occurs during development has long-lasting and particularly damaging effects on emotion. The basolateral amygdala (BLA) plays a key role in many affective behaviors, and repeated stress causes different forms of BLA hyperactivity in adolescent and adult rats. However, the mechanism is not known. Furthermore, not every individual is susceptible to the negative consequences of stress. Differences in the effects of stress on the BLA might contribute to determine whether an individual will be vulnerable or resilient to the effects of stress on emotion. The purpose of this study is to test the cellular underpinnings for age dependency of BLA hyperactivity after stress, and whether protective changes occur in resilient individuals. To test this, the effects of repeated stress on membrane excitability and other membrane properties of BLA principal neurons were compared between adult and adolescent rats, and between vulnerable and resilient rats, using in vitro whole-cell recordings. Vulnerability was defined by adrenal gland weight, and verified by body weight gain after repeated restraint stress, and fecal pellet production during repeated restraint sessions. We found that repeated stress increased the excitability of BLA neurons, but in a manner that depended on age and BLA subnucleus. Furthermore, stress resilience was associated with an opposite pattern of change, with increased slow afterhyperpolarization (AHP) potential, whereas vulnerability was associated with decreased medium AHP. The opposite outcomes in these two populations were further distinguished by differences of anxiety-like behavior in the elevated plus maze that were correlated with BLA neuronal excitability and AHP. These results demonstrate a substrate for BLA hyperactivity after repeated stress, with distinct membrane properties to target, as well as age-dependent factors that contribute to resilience to the effects of stress.

Neuropsychopharmacology (20I4) 39, 2 II4-2130; doi:I0.1038/npp.20I4.60; published online 2 April 20I4
\end{abstract}

\section{INTRODUCTION}

Adolescence, the transition period from childhood to adulthood, is associated with heightened perception of stress experience and greater responses to stress exposure compared with younger or older individuals (Compas et al, 1993; Allen and Matthews, 1997; Spear, 2000). Repeated or extreme stressors during adolescence lead to increased risk of depressive and anxiety behaviors, and there is a sharp increase in the incidence of psychiatric disorders during adolescence (Buchanan et al, 1992; Heim and Nemeroff, 2001; Teicher et al, 2003; Grant et al, 2006).

A similar pattern of adolescent vulnerability emerges in rodent models of stress. Immature rodents display greater

* Correspondence: Dr J Amiel Rosenkranz, Department of Cellular and Molecular Pharmacology, Chicago Medical School, Rosalind Franklin University of Medicine and Science, 3333 Green Bay Road, North Chicago, IL 60064, USA, Tel: + I 847578 8680, Fax: + I 847578 3268, E-mail: amiel.rosenkranz@rosalindfranklin.edu

Received 17 December 2013; revised 24 February 2014; accepted 27 February 20।4; accepted article preview online 12 March 2014 hormonal changes after stress than adults (Meaney et al, 1985; Sapolsky and Meaney, 1986; Walker et al, 1991; Romeo et al, 2006) and greater behavioral changes (Einon and Morgan, 1977; Stone and Quartermain, 1997; Hascoet et al, 1999; Spear, 2000; Luine et al, 2007; Toledo-Rodriguez and Sandi, 2007; Zhang and Rosenkranz, 2013). There are several brain regions that contribute to the effects of stress on affective behaviors. Primary among these regions is the basolateral amygdala (BLA). The BLA is sensitive to hormones (eg, glucocorticoids and corticotrophin-releasing hormone) that become elevated in response to stress (Rainnie et al, 1992; Duvarci and Pare, 2007; Sandi et al, 2008; Giesbrecht et al, 2010). Furthermore, repeated stress in rats leads to long-lasting changes in BLA-dependent behavior (Conrad et al, 1999; Toledo-Rodriguez and Sandi, 2007; Zhang and Rosenkranz, 2013) and BLA neuronal structure of adult rats (Vyas et al, 2002; Vyas et al, 2004; Padival et al, 2013b). Repeated stress also causes hyperactivity of BLA pyramidal neurons in adult rats in vivo (Rosenkranz et al, 2010; Zhang and Rosenkranz, 2012). The amygdala undergoes periadolescent developmental changes (Chareyron et al, 2012; Ehrlich et al, 2012; Ehrlich et al, 
2013). Therefore, age-dependent effects of stress on amygdala physiology are likely to occur. Recent studies demonstrate age-dependent changes in the firing of BLA neurons after repeated restraint stress (Zhang and Rosenkranz, 2012). However, the mechanism for these changes is not known. Neuronal excitability determines the firing response of BLA neurons, and could be a key target for the effects of stress. In line with this, previous studies demonstrate that the function of calcium-activated potassium $\left(\mathrm{K}_{\mathrm{Ca}}\right)$ channels that regulate BLA neuronal firing (Rainnie et al, 1993; Chen and Lang, 2003; Power and Sah, 2008), particularly SK channels, may be reduced in BLA neurons of adult rats after repeated stress (Rosenkranz et al, 2010). The purpose of this study is to test whether repeated stress leads to different effects on the excitability of BLA neurons in adult and adolescent rats, with an emphasis on functional correlates of SK channel activity (medium and slow afterhyperpolarization (AHP) potential).

Not every individual who experiences stress develops features of depression or anxiety (Rutter, 1985; Southwick et al, 2005; Alim et al, 2008). Previous studies have identified subpopulations in rodent models that are resilient to the effects of stress (Kabbaj, 2004; Bergstrom et al, 2007; Krishnan et al, 2007; Sandi et al, 2008; Feder et al, 2009; Schmidt et al, 2010; Wood et al, 2010; Blugeot et al, 2011; Stiller et al, 2011; Taliaz et al, 2011; Castro et al, 2012). An understanding of the factors that lead to stress-induced affective behaviors, and factors that protect against these effects, can lead to the development of new approaches to diminish stress-induced depression and anxiety. Therefore, this study will compare effects of repeated stress exposure on stress-responsive and nonresponsive populations. One of the commonly reported effects of repeated stress is increased anxiety-like behavior in the elevated plus maze (EPM; Caldji et al, 2000; Maslova et al, 2002; Vyas and Chattarji, 2004; Weiss et al, 2004; Pohl et al, 2007). Rats that are resilient to the cellular effects of repeated stress are also expected to be resilient to the behavioral effects. Not only are EPM measures responsive to stress, but they are also sensitive to manipulations of the BLA. Therefore, this study will include measures of anxiety-like behavior in the EPM to confirm resiliency measured by physiological approaches.

Despite known functional differences between lateral (LA) and basal (BA) nuclei of the BLA (Nader et al, 2001; Herry et al, 2008; Onishi and Xavier, 2010), few studies compare these nuclei, making it difficult to distinguish possible nucleus-selective differences in the effects of stress. Therefore, we examined membrane properties of projection neurons from both LA and BA nuclei in adolescent and adult rats. To further understand individual differences in the effects of stress on BLA-driven affective behavior, differences between stress-responsive and nonresponsive rats were compared in rats that underwent either control handling or repeated restraint stress, using in vitro electrophysiological recordings during adolescence and young adulthood.

\section{MATERIALS AND METHODS}

\section{Animals}

All studies were carried out in accordance with the Guide for the Care and Use of Laboratory Animals issued by the
National Institute of Health, and were approved by the Rosalind Franklin University of Medicine and Science Institutional Animal Care and Use Committee.

Two different age groups of male Sprague-Dawley rats (Harlan, Indianapolis, IN) were housed in groups of 2-3 per cage. Food and water were available ad libitum. Rats were maintained on a $12 \mathrm{~h}$ light/dark cycle with lights on at $0700 \mathrm{~h}$. Although there is no absolute age definition for adolescence in rats, Spear (2000) described an age range of approximately postnatal days (PNDs) $28-42$ in which rats would be expected to exhibit adolescent-typical behavioral characteristics. Adulthood can be defined as sexual maturity and occurs by PND 60 in rats (see, eg, Clermont and Perey, 1957; Korenbrot et al, 1977). Therefore, prepubertal rats arrived at PNDs 20-26, and young adult rats arrived at PNDs 53-63. Studies began after habituation to the animal facility for at least 5 days (PNDs $28-32$ or $60-70$ ). There was no significant difference in the age at the start of experiments or on the day of electrophysiology between the control and stress groups (adolescent control: $37.6 \pm 0.5$ days, stress: $37.9 \pm 0.5$ days; adult control: $72.4 \pm 0.3$ days, stress, $72.3 \pm 0.3$ days).

\section{Repeated Restraint Stress}

Repeated restraint stress was performed as previously described (Rosenkranz et al, 2010; Zhang and Rosenkranz, 2012), between 0930 and $1200 \mathrm{~h}$. Rats were randomly assigned to either control or stress group. Stress-group rats were placed in a restraint hemicylinder for $20 \mathrm{~min}$ per session, one session per day on 7 out of 9 consecutive days. Previous behavioral and electrophysiological studies demonstrate that this is an effective protocol to induce changes in BLA-dependent behaviors and BLA neuronal firing (Rosenkranz et al, 2010; Atchley et al, 2012; Zhang and Rosenkranz, 2012; Zhang and Rosenkranz, 2013). Three different sizes of restraint hemicylinders were used to fit the size of the rats such that movement of the body was restricted. Control rats were placed into individual clear transport cages with bedding for 20 min per session, once/ day, on 7 out of 9 consecutive days. The amount of handling was equal between the groups. As a measure of the level of stress, the number of fecal pellets during repeated restraint and control handling was counted and the mean number per session was calculated (total number of pellets/7 days). In addition, the weight was monitored daily throughout the sessions. Body weight gain over the course of stress was calculated as the weight 1 day after the last stress (or control) session subtracted by the weight on the first session.

\section{Elevated Plus Maze}

Increased anxiety-like behavior is a hallmark of responsiveness to repeated stress (Caldji et al, 2000; Maslova et al, 2002; Vyas and Chattarji, 2004; Weiss et al, 2004; Pohl et al, 2007). Therefore, at 1 day after the final control/stress session, the behavioral effectiveness of repeated stress was tested using the EPM (Scientific Designs, Pittsburgh, PA). Two EPM apparatus, scaled in size to fit either adolescent or adult rats, were used (Doremus et al, 2003; Doremus et al, 2004; Zhang and Rosenkranz, 2012). EPMs consisted of two 
open arms (without walls) and two closed arms (with high walls). Rats were placed in the center of the EPM, facing an open arm with free access to explore the entire apparatus for $5 \mathrm{~min}$ under dim light (25-30 lux). EPM was performed between 1000 and $1200 \mathrm{hm}$. Animal behavior was recorded and analyzed by a personal computer (Dell E6500) using Any-Maze software (Stoelting, Wood Dale, IL). The number of arm entries and the time spent in each arm were recorded. The number of arm entries and the relative amount of time spent in the open arms (time open arms $\div$ total time $(300 \mathrm{~s})$ ) were calculated. Rats that fell, climbed, or jumped down from the EPM during testing were excluded from data analysis ( $n=12$ rats). Increased adrenal weight is an additional marker of vulnerability to the effects of repeated stressors (Bassett and Cairncross, 1975; Dallman, 1984; Marquez et al, 2004). Therefore, both adrenal glands were removed and weighed after killing. The adrenal gland weight was normalized to the body weight of the animals (adrenal gland weight $\div$ total body weight) for analysis.

\section{Materials}

Compounds were obtained from Sigma-Aldrich (St Louis, MO) unless otherwise specified. $\mathrm{KCl}, \mathrm{NaCl}, \mathrm{NaH}_{2} \mathrm{PO}_{4}$, $\mathrm{NaHCO}_{3}$, dextrose, and $\mathrm{MgCl}_{2}$ were purchased from Fisher Scientific (Pittsburgh, PA).

\section{In Vitro Electrophysiology}

In vitro experiments were performed as described previously (Hetzel et al, 2012). Animals were anesthetized $(90 \mathrm{mg} / \mathrm{kg}$ ketamine (Ketaved) and $10 \mathrm{mg} / \mathrm{kg}$ xylazine (Anased), Webster Veterinary Supply, Sterling, MA) and perfused transcardially using ice-cold, aerated $\left(95 \% \mathrm{O}_{2} / 5 \%\right.$ $\mathrm{CO}_{2}$ ), high sucrose artificial cerebrospinal fluid (ACSF) containing (in mM) $2.5 \mathrm{KCl}, 1.25 \mathrm{NaH}_{2} \mathrm{PO}_{4}, 25 \mathrm{NaHCO}_{3}, 7$ dextrose, $7 \mathrm{MgCl}_{2}, 0.5 \mathrm{CaCl}_{2}, 210$ sucrose, 1.3 ascorbic acid, and 3 sodium pyruvate. Osmolality of high sucrose ACSF was $\sim 290 \mathrm{mOsm}$. The rate of perfusion was $\sim 4 \mathrm{ml} / \mathrm{min}$ with a total volume of $20-30 \mathrm{ml}$. Rats were decapitated and the brain was removed quickly. After sectioning horizontally at $300 \mu \mathrm{m}$ in a vibratome (Ted Pella, Redding, CA) in ice-cold high sucrose ACSF, the brain slices were recovered for $\sim 1 \mathrm{~h}$ at $34{ }^{\circ} \mathrm{C}$ in physiological ACSF containing (in mM) $125 \mathrm{NaCl}, 2.5 \mathrm{KCl}, 1.25 \mathrm{NaH}_{2} \mathrm{PO}_{4}, 25 \mathrm{NaHCO}_{3}, 10$ dextrose, $1 \mathrm{MgCl}_{2}$, and $2 \mathrm{CaCl}_{2}$, with the addition of $1.3 \mathrm{mM}$ ascorbic acid and $3 \mathrm{mM}$ sodium pyruvate. Recordings were performed at $30-34{ }^{\circ} \mathrm{C}$ in submerged slices in physiological extracellular ACSF. (+)-bicuculline $(10 \mu \mathrm{M}$; Ascent Scientific, Princeton, NJ; dissolved in dimethyl sulfoxide), picrotoxin $(10 \mu \mathrm{M}$; dissolved in ethanol), 6-cyano-7-nitroquinoxaline-2,3-dion (CNQX) disodium salt $(10 \mu \mathrm{M}$; Ascent Scientific; dissolved in $\mathrm{ddH}_{2} \mathrm{O}$ ), and DL-2-Amino-5-phosphonopentanoic acid (DL-AP5) sodium salt (50 $\mu \mathrm{M}$; Abcam Biochemicals, Cambridge, MA; dissolved in $100 \mathrm{mM} \mathrm{NaOH}$ ) were added to the ACSF for all experiments to block $\mathrm{GABA}_{\mathrm{A}^{-}}$, AMPA-, and NMDA receptor-mediated currents. Final solvent concentrations were $<0.1 \%$ of the total ACSF volume. Solutions were continuously aerated with $95 \%$ $\mathrm{O}_{2} / 5 \% \mathrm{CO}_{2}$. Electrodes (1.8-11.3 $\mathrm{M} \Omega$ open tip resistance) were filled with an intracellular solution containing (in $\mathrm{mM}$ )
$120 \mathrm{~K}$-gluconate, $20 \mathrm{KCl}, 0.2$ EGTA, 10 HEPES, $2 \mathrm{NaCl}, 4$ ATP-Mg, 0.3 GTP-Tris, 7 tris-phosphocreatine, and $0.2 \%$ neurobiotin (Vector Laboratories, Burlingame, CA), with a $\mathrm{pH}$ of 7.3 .

Whole-cell recordings were performed in bridge mode from visually identified pyramidal neurons within the BA and LA (AxoClamp 2B, Molecular Devices, Sunnyvale, $\mathrm{CA}$ ). Signals were low-pass filtered at $3-5 \mathrm{kHz}$ and digitalized at $10 \mathrm{kHz}$ (ITC-18, Heka Instruments, Bellmore, NY). Mean series resistance for each group was $<25 \mathrm{M} \Omega$. All electrophysiology data were monitored with AxoGraph X software version 1.3.5 (Axograph Scientific) and stored on a computer (Mac Pro, Apple) for off-line analysis.

The resting membrane potential $\left(\mathrm{V}_{\text {rest }}\right)$ of each cell was noted. Recordings from cells with a $\mathrm{V}_{\text {rest }}$ above $-60 \mathrm{mV}$ were discontinued. To measure excitability, depolarizing current steps were applied (0-250 pA, $50 \mathrm{pA}$ increments, $1 \mathrm{~s}$, repeated 3 times) from a membrane potential of $-70 \mathrm{mV}$. The mean number of action potentials (APs) during each depolarization step was plotted against the amount of current injected. A single numerical measure of excitability $\left(\mathrm{EC}_{50}\right.$; the current intensity that evoked half-maximal firing between 0 and $250 \mathrm{pA}$ ) was derived for use in correlational analysis. The $\mathrm{EC}_{50}$ was calculated from a best-fit to the current intensity-action potential firing excitability curve (above). AP duration of a single AP was measured as the AP width at half-maximal amplitude. Input resistance (Rn) was measured as a linear fit of the voltage response to hyperpolarizing current pulses $(0$ to $-50 \mathrm{pA},-10 \mathrm{pA}$ increments, $1 \mathrm{~s}$, repeated twice). Membrane potential for Rn measurement was $-70 \mathrm{mV}$. Larger hyperpolarizing current steps were applied ( 0 to $-400 \mathrm{pA},-100 \mathrm{pA}$ increments, $1 \mathrm{~s}$, repeated 3 times) from a membrane potential of $-60 \mathrm{mV}$ to measure voltage sag, reflective of hyperpolarization-activated cyclic nucleotide-gated channel (h channel) function. The amplitude of the peak hyperpolarization and the steady-state voltage response during hyperpolarizing steps were measured. The sag ratio (peak response $\div$ steady-state response) was calculated for analysis. The medium and slow AHPs (mAHP and sAHP) were measured as the response to a train of 5 depolarizing current pulses $(10 \mathrm{~ms}$ at $700 \mathrm{pA}$ each, evoking a train of $5 \mathrm{APs}$ ) at $50 \mathrm{~Hz}$, from a membrane potential of $-55 \mathrm{mV}$. Only AHPs elicited by 1 AP per $10 \mathrm{~ms}$ depolarization pulse were used for analysis. The train was repeated 10 times (10-20 s intervals) and the average AHP response was measured. The MAHP (at AHP peak) and the sAHP (270-300 ms) amplitudes were analyzed separately. The AHP amplitude was calculated by subtraction from the preburst baseline membrane potential.

\section{Histology}

After recordings, slices were fixed in $4 \%$ paraformaldehyde in $0.1 \mathrm{M}$ phosphate-buffered saline (PBS) for up to 4 weeks at $4{ }^{\circ} \mathrm{C}$. Sections were rinsed three times with PBS, treated with Triton X-100 (VWR International, Radnor, PA; $1 \%$ in PBS) for $6-8 \mathrm{~h}$, and then incubated in the Vectastain $\mathrm{ABC}$ Reagent (Vector Laboratories) in PBS at room temperature overnight. After three rinses with $\mathrm{PBS}$, sections were reacted with diaminobenzidine (DAB) and $\mathrm{H}_{2} \mathrm{O}_{2}$ (Peroxidase Substrate Kit DAB, Vector Laboratories) in water to 
visualize the neurobiotin-filled neurons. Sections were washed in PBS repeatedly to stop the reaction. Sections were mounted, dried, and coverslipped. Stained sections were used to localize the recording sites, verified by the position of the filled neurons. Neurons were considered BA or LA principal neurons if they were histologically confirmed to lie within the BA or LA nuclei of the amygdala and had a morphology consistent with pyramidal neurons (McDonald, 1982, 1984).

\section{Statistical Analysis}

Unless stated otherwise, data are expressed as mean \pm SEM throughout the text and in figures. The $\alpha$-level was set at 0.05 for statistical significance. Statistical significance was determined by using two-tailed unpaired $t$-test when comparing two groups, and one-way ANOVA when comparing more than two groups (Prism version 5.0c, GraphPad Software, La Jolla, CA). When multiple measures were compared between groups (eg, input-output curves) a repeated measures two-way ANOVA was used. Two-way ANOVAs were followed by Tukey's posttests when the interaction was statistically significant. Before statistical analysis, normality of distribution was determined using D'Agostino and Pearson normality test. If data sets were found to display nonnormal distributions, nonparametric analysis was used (Kruskal-Wallis with post hoc Dunn's tests). Correlational analysis was performed by determination of the best-fit linear regression and Pearson's correlation coefficient. Because multiple neurons were recorded from single rats in some instances, the electrophysiology values from single animals were averaged together before correlation analysis. The $p$-values were corrected for multiple correlations by Bonferroni adjustments based on the number of correlations. The $p$-values have been reported after post hoc corrections.

Responders and nonresponders to stress. Initial analysis tested for outliers from the distribution of adrenal gland weights. Outliers were defined as $>2$ SDs from the average adrenal gland weight. Data from those rats were removed from analysis ( $n=3$ adolescent rats, $n=4$ adult rats). Distributions of adrenal gland weights were further examined to test whether the data were best fit by a single Gaussian (unimodal) or summation of two Gaussians (bimodal; best-fit test, with null hypothesis of single Gaussian). If data were best-fit with two Gaussians, data were split into two populations. The dividing point of the two populations was at the intersection of the two Gaussians (determined by reading the value from the graphical plot). The population of stress-exposed rats with lower adrenal gland weight will be termed 'nonresponders,' and the population with higher adrenal gland weight will be termed 'responders' in the text below.

\section{RESULTS}

\section{Subpopulations of Responsiveness to Repeated Restraint Stress}

Repeated restraint was used to model stress. A total of 55 adolescent (control: $n=24$ rats, stress: $n=31$ rats) and 92 adult rats (control: $n=46$ rats, stress: $n=46$ rats) were
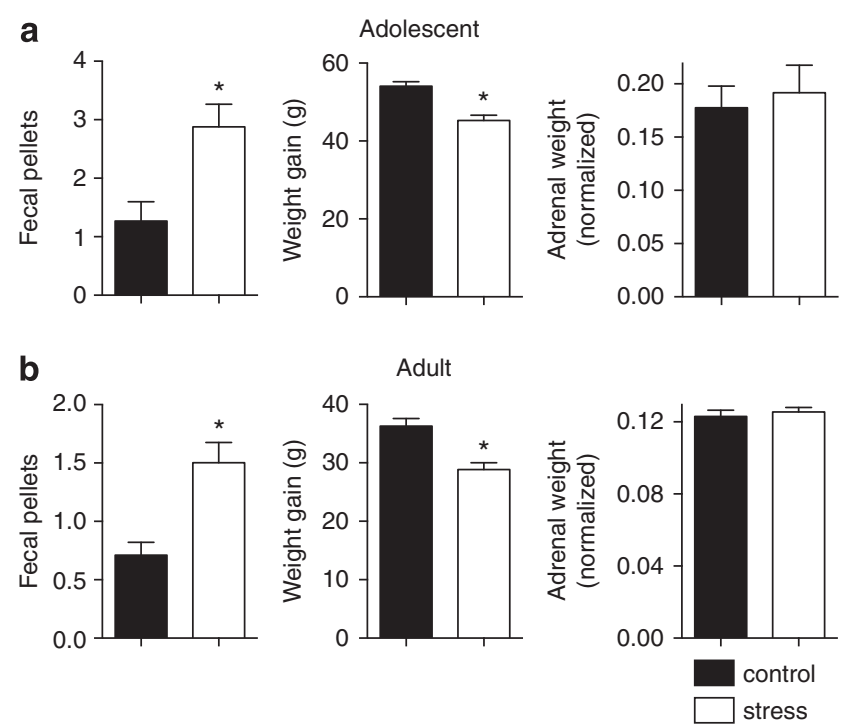

Figure I Repeated restraint is an effective stressor. (a) In adolescent rats, fecal pellet production during restraint sessions was significantly greater than fecal pellet production during an equivalent time control session (left). Weight gain was significantly less in adolescent rats exposed to repeated restraint compared with control rats (middle), and there was a trend toward increased adrenal gland weight (right). (b) In adult rats, fecal pellet production during restraint sessions was significantly greater than fecal pellet production during controls sessions (left). Weight gain was significantly less in adult rats exposed to repeated restraint compared with control rats (middle), and there was a trend toward increased adrenal gland weight. ${ }^{*} p<0.05$ in two-tailed unpaired t-test.

included in this study. To evaluate the effectiveness of our stress protocol, we (1) measured the mean number of fecal pellets per stress/control session, (2) measured the weight gain over the period of stress/control handling, (3) measured the level of anxiety-like behavior using EPM, and (4) measured the adrenal gland weight. Both adolescent and adult rats had a significantly higher mean number of fecal pellets per day during the stress session than during control handling (Figure 1a and b, left, $\sim 200 \%$ increase in both groups; adolescent control $1.27 \pm 0.33$, stress $2.88 \pm 0.36,227 \%$ increase, $p=0.004$, two-tailed unpaired $t$-test; adult control $0.71 \pm 0.11$, stress $1.50 \pm 0.17,211 \%$ increase, $p=0.002$, two-tailed unpaired $t$-test). Weight gain was significantly reduced over the length of the experiment in stressed animals of both age groups when compared with their controls (Figure 1a and b, adolescent control $54.1 \pm$ $1.2 \mathrm{~g}$, stress $45.3 \pm 1.4 \mathrm{~g}, p<0.0001$, two-tailed unpaired $t$-test; adult control $36.3 \pm 1.3 \mathrm{~g}$, stress $28.9 \pm 1.2 \mathrm{~g}$, $p=0.0001$, two-tailed unpaired $t$-test).

Although the data show a trend toward an increase in the normalized adrenal gland weight in adolescent as well as adult rats after repeated restraint stress, this difference was not significant (Figure 1a and b; adolescent control $0.178 \pm 0.004$, stress $0.191 \pm 0.005, p=0.053$, two-tailed unpaired $t$-test; adult control $0.123 \pm 0.004$, stress $0.127 \pm$ $0.003, p=0.54$, two-tailed unpaired $t$-test). However, upon examination of the distribution of adrenal gland weights, a bimodal pattern emerged after stress, consistent with stressresponsive (high adrenal weight) and stress-nonresponsive (low adrenal weight) subpopulations. 
Adolescents: Distribution of adrenal gland weights. In adolescent rats, the distribution of normalized adrenal weights in control rats was best fit by a single Gaussian instead of the sum of two Gaussians (Figure 2a; $p=0.94$; $\mathrm{F}(3,6)=0.12$, mean $=0.17$, see Materials and Methods). However, in rats exposed to repeated stress the distribution was best fit by a sum of two Gaussians (Figure 2a; $p=0.004$, $\left.\mathrm{F}(3,6)=14.5 ; \operatorname{mean}_{1}=0.17, \operatorname{mean}_{2}=0.21\right)$. The two Gaussians were used to delineate between stress-nonresponsive and stress-responsive populations (see Materials and Methods). To verify this division, the parameters that describe the Gaussians were compared. A comparison of best-fit parameters yielded significant differences between the stress-responsive (Figure 2 c; $n=24$ rats, mean $=0.20$, $\mathrm{SD}=0.026)$ and the stress-nonresponsive distribution of adrenal gland weight (Figure $2 \mathrm{c} ; n=7$ rats, mean $=0.16$, $\mathrm{SD}=0.010 ; p<0.0001, \mathrm{~F}(2,14)=45.6$, extra sum-of-squares F-test) or controls (Figure 2 c; $n=20$ rats, mean $=0.167$, $\mathrm{SD}=0.012 ; \quad p<0.0001, \quad \mathrm{~F}(2,18)=25.6)$. There was no significant difference between the best-fit parameters for the adrenal gland weight distributions of nonresponsive and control rats $(p=0.062, \mathrm{~F}(2,8)=2.18)$, consistent with a group of adolescent rats that were not significantly affected by repeated stress.

Adults: Distribution of adrenal gland weights. Similarly, in adult rats, the distribution of normalized adrenal weights in control rats was best fit by a single Gaussian (Figure $2 \mathrm{~b} ; p=0.26 ; \mathrm{F}(3,3)=2.24$, mean $=0.11$ ). However, in rats exposed to repeated stress, the distribution was best fit by a sum of two Gaussians $(p=0.009, \mathrm{~F}(3,3)=32.9$; mean $_{1}=0.10$, mean $_{2}=0.13$ ). In adult rats, comparison of best-fit parameters yielded significant differences between the stress-responsive (Figure $2 \mathrm{~d} ; n=34$ rats, mean $=0.13$, $\mathrm{SD}=0.008)$ and the stress- nonresponsive distribution of normalized adrenal gland weights (Figure $2 \mathrm{~d} ; n=8$ rats, mean $=0.10, \quad \mathrm{SD}=0.013 ; p<0.0001, \quad \mathrm{~F}(2,12)=29.8)$ or control (Figure 2d; $n=24$ rats, mean $=0.11, S D=0.011$; $p<0.0001, F(2,12)=60.1)$. There was no significant difference in the mean of the Gaussian best-fit distributions between the nonresponsive and the control rats $(p=0.20$, $\mathrm{F}(2,6)=2.12$ ), further evidence for a subpopulation of adult rats that were not strongly affected by repeated stress.

To further complement the division into responders and nonresponders based on adrenal weight, body weight gain was analyzed after subdivision into responders and nonresponders. There was a significant difference in adolescent body weight gained when control, nonresponders, and responders were compared (Figure $2 \mathrm{c} ; p=0.0004$, $\mathrm{F}(2,50)=9.35$, one-way ANOVA), with significant differences between responders and controls $(p<0.05$, post hoc Tukey's test) and between responders and nonresponders $(p<0.05$, post hoc Tukey's test). Similarly, in adults, there was a significant difference in weight gain across groups (Figure 2d; $p<0.0001, \mathrm{~F}(2,63)=12.8$, one-way ANOVA), with significant differences ( $p<0.05$, post hoc Tukey's test) between responders and control, and between responders and nonresponders. In a similar manner, fecal production during restraint was compared between responders and nonresponders. There was a significant difference in fecal production when control, nonresponders, and responders
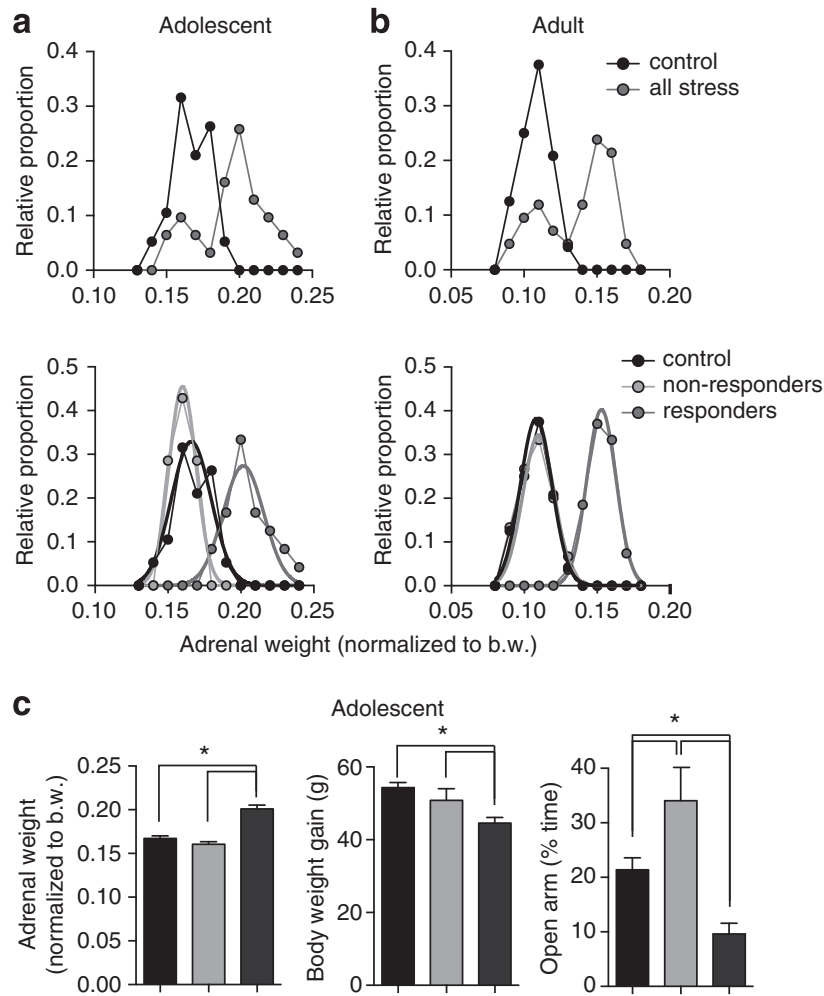

d
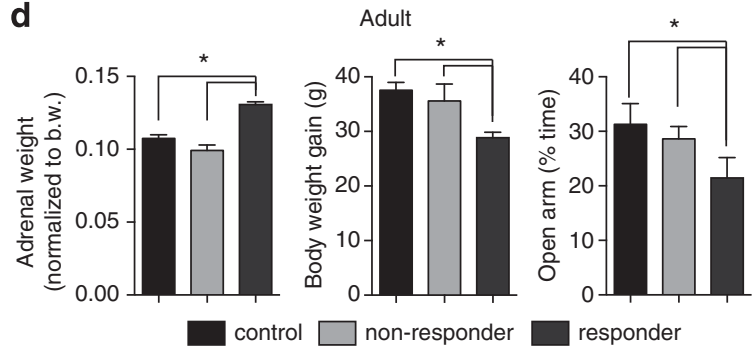

Figure 2 Two populations of responses to repeated restraint stress (a) The distribution of adrenal gland weights in adolescent control (black, top) and stress-exposed (dark gray, top) rats indicates a subset of stressexposed rats with adrenal gland weights similar to controls, whereas the majority of stress-exposed rats had greater adrenal gland weight (top). Adrenal gland weight data from control rats were best fit by a single Gaussian (bottom, black), whereas data from stress-exposed rats were best fit by the sum of two Gaussians (indicative of two populations), one with a mean similar to controls (light gray, bottom, nonresponders), and one with a mean greater than controls (dark gray, bottom, responders). (b) Similarly, in adult rats there was evidence of overlapping adrenal gland weight distributions of control (black, top) and stress-exposed rats (dark gray, top). Adrenal gland weight distributions from stress-exposed adult rats was also best fit by the sum of two Gaussians, one with a mean similar to control rats (light gray, bottom, nonresponders), and one with a mean greater than controls (dark gray, bottom, responders). (c) In adolescent rats, a significant difference in adrenal gland weight (left), body weight gain (middle), and open arm exploration (percent time in open arm, right) is observed between stress responders and nonresponders. (d) Similarly, in adult rats, a significant difference in adrenal gland weight (left), body weight gain (middle), and open arm exploration (percent time in open arm, right) is observed between stress responders and nonresponders. $* P<0.05$, oneway ANOVA, followed by post hoc Tukey's test. The colour reproduction of this figure is available on the html full text version of the manuscript.

were compared in adolescents (Supplementary Figure 1A; $p=0.01, \quad \mathrm{~F}(2,50)=5.12$, one-way ANOVA; significant differences between responders and control, and between 
responders and nonresponders, $p<0.05$ post hoc Tukey's test) and in adults (Supplementary Figure 1B; $p=0.009$, $\mathrm{F}(2,63)=5.1$, one-way ANOVA; significant differences between responders and control, and between responders and nonresponders, $p<0.05$ post hoc Tukey's test).

The subdivision of rats into stress responders and nonresponders based on adrenal weight was further explored in analysis of anxiety-like behavior in the EPM in a group of rats. The behavioral values were not normally distributed $(p<0.001$, D'Agostino and Pearson normality test) in adult or adolescent rats, and hence further analysis was performed with nonparametric analysis. Rats in the control, stress-responsive and stress-nonresponsive groups were compared. There was a significant difference in exploration of open arms (percent time) across groups in adolescent rats (Figure 2c; $p=0.014$, Kruskal-Wallis test $=8.53$; control, $n=16$; nonresponders, $n=6$; and responders, $n=24)$, with significant differences between control and responders (control, $21.4 \pm 2.2 \%$, responders, $9.6 \pm 2.0 \%, p<0.05$, Dunn's test) and nonresponders and responders (nonresponders, $34.1 \pm 8.1 \%$; responders, $9.6 \pm 2.0 \%, p<0.05$, Dunn's test).

The same effect was observed in adult rats, with a significant difference in exploration of open arms across groups (Figure 2d; $p<0.0001$, Kruskal-Wallis test $=24.0$; control, $n=22$; nonresponders, $n=8$; and responders, $n=30$ ), with significant differences between control and responders (control, $31.3 \pm 3.8 \%$; responders, $21.4 \pm 3.8 \%$; $p<0.05$, Dunn's test) and nonresponders and responders (nonresponders, $28.6 \pm 2.3 \%$; responders, $21.4 \pm 3.8 \%$, $p<0.05$, Dunn's test).

There was no difference in the number of total arm entries between adolescent groups (control, 19.0 \pm 1.0 entries; nonresponders, $19.0 \pm 2.9$ entries; responders, $16.2 \pm 1.0$ entries, $p=0.17, \quad \mathrm{~F}(2,42)=1.83$, one-way ANOVA) or adult groups (control, $17.5 \pm 0.9$ entries; nonresponders, $15.1 \pm 1.1$ entries; responders, $17.5 \pm 0.8$ entries, $p=0.36, \mathrm{~F}(2,57)=1.05$, one-way ANOVA), indicating no effect of repeated restraint stress on overall locomotor activity.

The behavioral and physiological measures above support the presence of two types of outcomes in response to repeated stress: a nonresponsive group that is resilient to the anxiogenic effects of repeated stress, and a stressresponsive group that is vulnerable to the anxiogenic effects of repeated stress. Therefore, initial analysis below compared control and stress treatment, with secondary analysis of stress responders and nonresponders.

\section{Effects of Stress on Adolescent Amygdala}

At 1 day after the last stress/handling session, and $\sim 1 \mathrm{~h}$ after EPM, amygdala slices were prepared. Membrane properties of pyramidal neurons in the BA and LA were recorded. Only cells that displayed characteristic pyramidal electrophysiological properties were included in this study (Washburn and Moises, 1992; Rainnie et al, 1993; Lang and Pare, 1997; Faber et al, 2001). Characteristic properties included lack of spontaneous discharge at rest, broad action potentials ( $>1.1 \mathrm{~ms}$ half-width), and spike frequency adaptation upon injection of depolarizing current. In addition, location and pyramidal-like morphology of LA and BA neurons were confirmed after staining for neurobiotin (Supplementary Figure 2).

Repeated stress increases the excitability of neurons in the basal nucleus of adolescent rats. The number of action potentials in response to depolarizing current injections was used to measure neuronal excitability. Repeated stress significantly increased the excitability of BA neurons in adolescent rats (Figure $3 \mathrm{a}$ and $\mathrm{b} ; \mathrm{F}_{\text {interaction }}(5,350)=3.399$, $p=0.0052$, two-way repeated measures ANOVA). This impact of repeated stress was also observed in rats not exposed to EPM (control $=12$ neurons, stress $=11$ neurons, $\mathrm{F}_{\text {interaction }}(5,105)=6.65, p<0.001$, two-way repeated measures ANOVA; Supplementary Figure 3A). When subdivided into controls, nonresponders, and responders based on adrenal gland weight (above), there was a similar interaction (Figure $3 c ; \mathrm{F}_{\text {interaction }}(10,305)=1.9, p=0.04$, two-way repeated measures ANOVA; controls $n=26$ neurons, nonresponders $n=12$ neurons, responders $n=26$ neurons), with significantly greater excitability in the stress responders compared with controls at higher current intensity $(p<0.05$, post hoc Tukey's test at 200 and $250 \mathrm{pA})$. BA neuronal excitability of the nonresponders was not significantly different than the control group at any current intensity ( $p>0.05$, post hoc Tukey's test at $0-250 \mathrm{pA})$. In addition to excitability, other differences between BA neurons from stress-responsive and stressnonresponsive groups emerged. The stress-nonresponsive group displayed significantly greater sAHP amplitude in BA neurons (Figure $4 \mathrm{a}-\mathrm{d} ; p=0.028, \mathrm{~F}(2,56)=3.80$, one-way ANOVA; nonresponders significantly greater than control and responders, $p<0.05$ post hoc Tukey's test), and voltage sag during prolonged current injection (Figure 4g, Table 1; $p=0.0034, \mathrm{~F}(2,69)=6.18$, one-way ANOVA; control significantly greater than responders, nonresponders significantly greater than control and responders, $p<0.05$ post hoc Tukey's test). Increased sAHP and voltage sag can serve to dampen excitability of BA neurons in nonresponders. There were no significant effects on MAHP amplitude (Figure $4 \mathrm{c}$; $p=0.13, \mathrm{~F}(2,56)=2.13$, one-way ANOVA) or input resistance (Rn; Table $1, p=0.68, F(2,61)=0.39$, one-way ANOVA). Thus, overall, repeated stress decreased the sAHP and increased excitability of BA neurons. However, repeated stress increased excitability of BA neurons in stressresponsive adolescent rats, but not the stress-nonresponsive adolescent rats, and this was associated with increased sAHP and voltage sag in the stress nonresponders compared with stress responders.

Repeated stress increases the excitability of neurons in the lateral nucleus of adolescent rats. Repeated stress also increased excitability of LA neurons in adolescent rats (Figure 3d and e; $F_{\text {interaction }}(5,195)=5.8, p<0.0001$, two-way repeated measures ANOVA). This impact of repeated stress was also observed in rats not exposed to $\mathrm{EPM} \quad$ (control $=8$ neurons, stress $=8$ neurons, $\mathrm{F}_{\text {interaction }}(5,70)=2.51, p=0.038$, two-way repeated measures ANOVA; Supplementary Figure 3B). When subdivided into controls, nonresponders, and responders based on adrenal gland weight (above), there was a similar interaction (Figure 3f; $\mathrm{F}_{\text {interaction }}(10,190)=3.1, \quad p=0.0013$, 


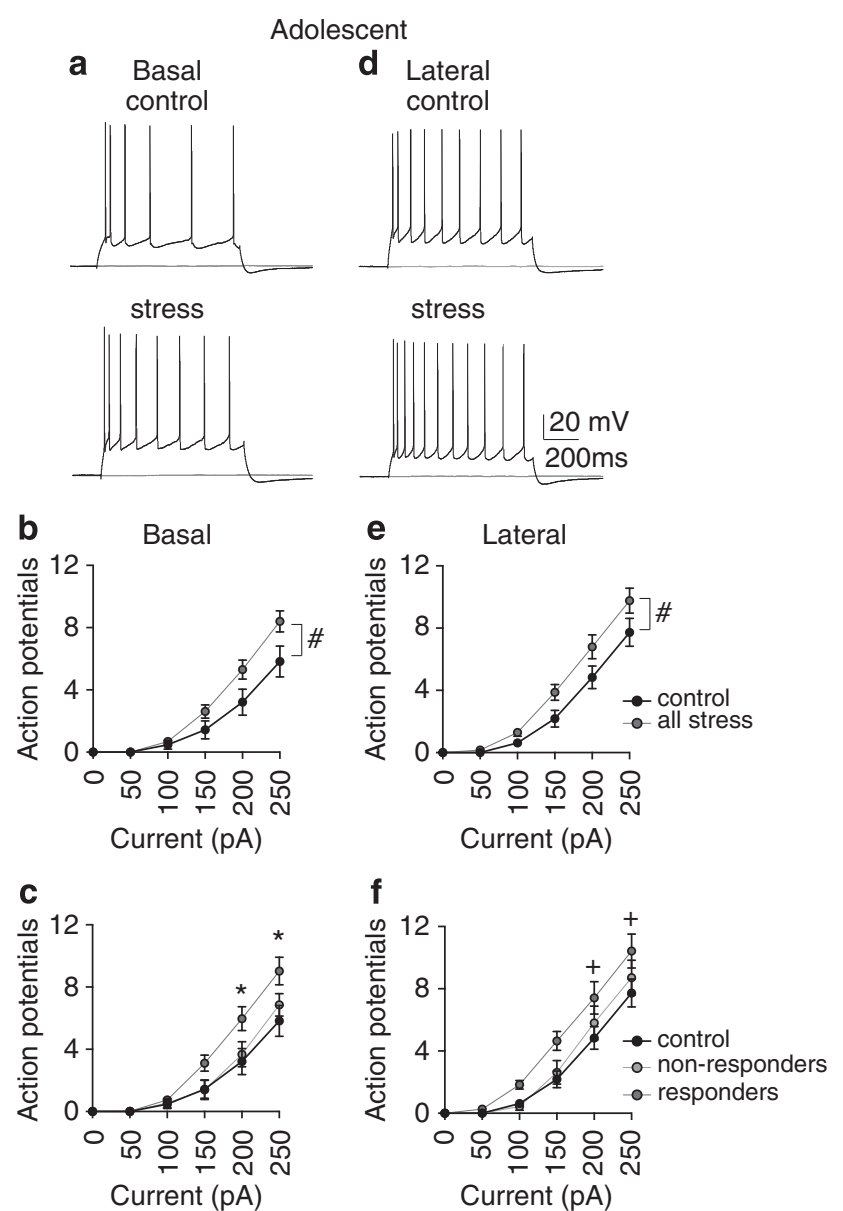

Figure 3 Repeated restraint increases excitability of BA and LA neurons in adolescent rats. (a) Excitability was measured as the firing response to a range of depolarizing current steps. Repeated stress increased the excitability of BA neurons. (b) This increased excitability was observed over a range of current steps in BA neurons. (c) There was a significant difference in excitability of BA neurons from stress-responsive and stressnonresponsive rats. (d) Repeated stress increased excitability of LA neurons in adolescent rats. (e) The increased excitability of LA neurons was observed over a range of current steps. (f) Excitability of LA neurons from stress-responsive rats displayed significantly greater excitability than control rats. Excitability of LA neurons in nonresponsive rats was intermediate, without being significantly different from control rats. ${ }^{\#} p<0.05$, significant interaction in two-way repeated measures ANOVA. $* p<0.05$ between stress-responsive and stress-nonresponsive rats, and between stressresponsive and control rats after two-way repeated measures ANOVA followed by post hoc Tukey's test. ${ }^{+} p<0.05$ between stress-responsive and control rats after two-way repeated measures ANOVA followed by post hoc Tukey's test.

two-way repeated measures ANOVA; controls $n=19$ neurons, nonresponders $n=10$ neurons, and responders $n=17$ neurons), with significantly greater excitability in LA neurons from stress responders compared with controls at higher current intensity ( $p<0.05$, post hoc Tukey's test at 200 and 250 pA). Excitability of LA neurons from adolescent nonresponders was not significantly different than controls at any current intensity $(p>0.05$, post hoc Tukey's test at $0-250 \mathrm{pA})$.

Despite similarities in the effects of stress on LA and BA neuronal excitability in adolescent rats, stress was associated with a different pattern of membrane property changes in LA neurons. There was no significant effect of stress on sAHP amplitude (Figure $4 \mathrm{f} ; p=0.46, \mathrm{~F}(2,37)=$ 0.80 , one-way ANOVA) or voltage sag (Figure $4 \mathrm{~h} ; p=0.86$, $\mathrm{F}(2,38)=0.16$, one-way ANOVA) in LA neurons of adolescent rats. In contrast, stress was associated with decreased mAHP amplitude (Figure $4 \mathrm{e} ; p=0.04, \mathrm{~F}(2,37)=3.42$, oneway ANOVA) in LA neurons of adolescent rats, with significantly smaller $\mathrm{mAHP}$ in responders compared with controls and nonresponders $(p<0.05$, post hoc Tukey's test). Thus, repeated stress increased excitability of LA neurons in adolescent rats, and this was associated with a decreased mAHP in stress-responsive as compared with stress-nonresponsive rats. Decreased mAHP can serve to increase excitability of LA neurons in stress-responsive rats.

The effects of stress in adolescent rats were further explored using correlational analysis. Adrenal weight of adolescent rats was correlated with firing of BA neurons $\left(\mathrm{EC}_{50} ;\right.$ Figure 5a, left; $\left.r=-0.65, p<0.0001\right)$ and LA neurons (Figure 5a, right; $r=-0.57, p=0.0024$ ). Adrenal weight was significantly correlated with sAHP of BA neurons (Figure $5 c ; r=0.53, p=0.002$ ), but mAHP of LA neurons (Figure 5b; $r=0.61, p=0.003$ ). Similarly, exploration of open arms in the EPM was significantly correlated with BA neuronal sAHP $(r=-0.59, p=0.0004)$, but LA neuronal mAHP $(r=-60, p=0.002)$, adding further weight to the role of AHPs in stress responsiveness of BLA neurons. These data are consistent with the impact of repeated stress on excitability, and a role for sAHP in $\mathrm{BA}$ neurons, but the mAHP in LA neurons of adolescent rats, in vulnerability to the effects of repeated stress.

\section{Effects of Stress on Adult Amygdala}

Adult rats were treated in the same manner as adolescent rats. At 1 day after the last stress/handling session and $\sim 1 \mathrm{~h}$ after EPM, amygdala slices were prepared from adult rats. As described above, neurons from the BA and LA were recorded. Neuronal morphology and location were confirmed after staining for neurobiotin (Supplementary Figure 2).

Repeated stress does not increase the excitability of neurons in the basal nucleus of adult rats. Excitability was measured in adult rats in the same manner as adolescent rats. However, stress did not significantly change the excitability of BA neurons in adult rats (Figure $6 \mathrm{a}$ and $\mathrm{b}$; $\mathrm{F}_{\text {interaction }}(5,315)=0.23, \quad p=0.95 ; \quad \mathrm{F}_{\text {treatment }}(1,63)=0.13$, $p=0.72$, two-way repeated measures ANOVA). An effect of repeated stress was also absent in rats not exposed to $\mathrm{EPM}$ (control $=12$ neurons, stress $=14$ neurons, $\mathrm{F}_{\text {interaction }}(5,120)=0.10, p=0.42$, two-way repeated measures ANOVA; Supplementary Figure 3C). This surprising result was further examined by subdivision into control and stress nonresponders and responders with the same result (Figure $6 c ; F_{\text {interaction }}(10,310)=0.57, p=0.84$; $\mathrm{F}_{\text {treatment }}(2,62)=0.71, p=0.50$, two-way repeated measures ANOVA; control $n=33$ neurons, nonresponders $n=11$ neurons, responders $n=32$ neurons). Furthermore, there were no significant effects of stress on mAHP, sAHP, voltage sag, or $\mathrm{Rn}$ of $\mathrm{BA}$ neurons from adult rats (Table 1 and Figure $7 \mathrm{a}-\mathrm{c}$ and $\mathrm{f}$ ). 
a

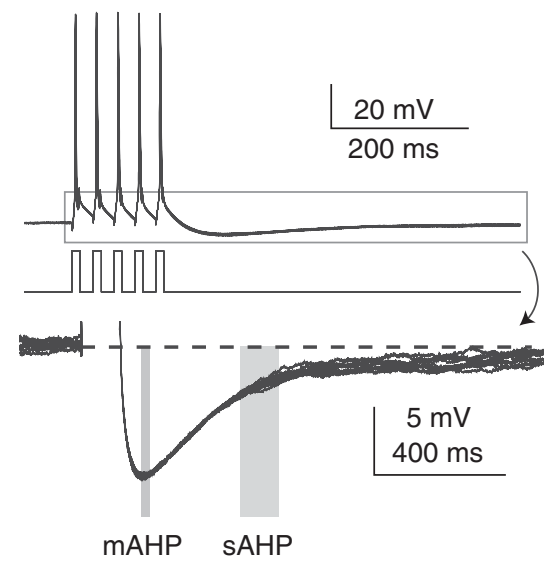

b

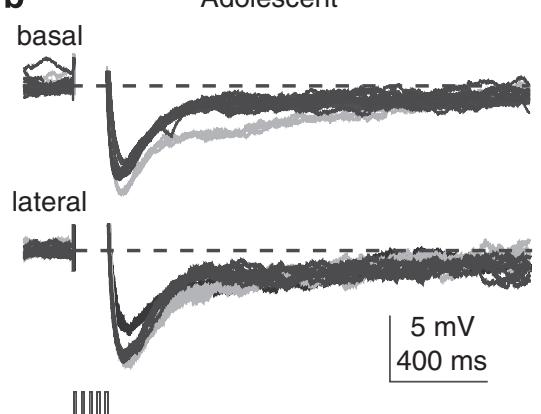

C
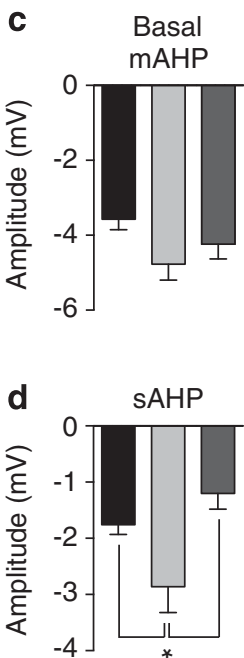

g e Lateral

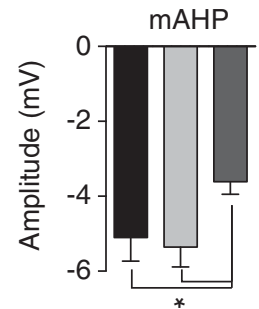

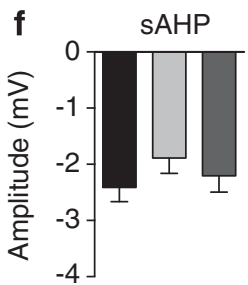

h voltage sag

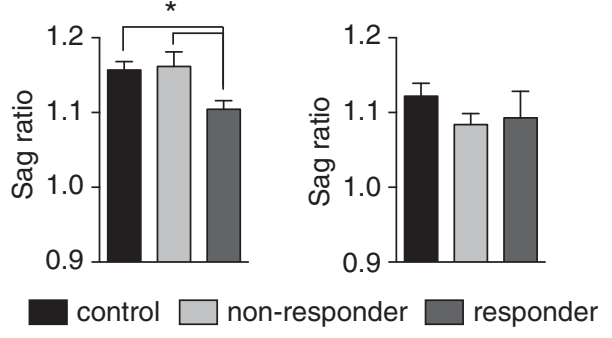

control $\square$ non-responder $\square$ responder

Figure 4 Effects of repeated restraint on AHP of BLA neurons in adolescent rats. (a) Medium and slow AHPs indicative of SK channel function were elicited by a burst of 5 action potentials induced by 5 brief $(10 \mathrm{~ms})$ current steps at $50 \mathrm{~Hz}$. The medium AHP (mAHP) amplitude was measured from the peak of the AHP, whereas the slow AHP (sAHP) was measured at 570-600 ms from the burst of action potentials. (b) The sAHPs were particularly larger in BA neurons from nonresponsive rats (top, light gray) compared with control rats (black) and stress-responsive rats (dark gray). In contrast, the shorter latency mAHP was smaller in LA neurons from stress-responsive rats (bottom, dark gray) compared with nonresponsive (light gray) and control rats (black). (c) In BA neurons, there was no significant difference in mAHP amplitude between control, nonresponsive, or responsive groups. (d) However, there was a significantly greater sAHP amplitude in BA neurons from nonresponsive rats, compared with control and responsive rats. (e) In LA neurons, the mAHP amplitude was significantly smaller in responsive rats compared with nonresponsive and control rats. ( $f$ ) However, there was no significant difference in the sAHP amplitude of LA neurons between groups. (g) In BA neurons, there was a significantly smaller voltage sag ratio in responders after repeated stress. (h) However, there was no significant effect of repeated stress on voltage sag ratio in LA neurons. * $p<0.05$ in one-way ANOVA followed by post hoc Tukey's test. The colour reproduction of this figure is available on the html full text version of the manuscript.

Repeated stress increases the excitability of neurons in the lateral nucleus of adult rats. In contrast to BA, repeated stress increased the excitability of LA neurons in adult rats (Figure $6 \mathrm{~d}$ and e; $F_{\text {interaction }}(5,225)=4.09, p=0.0014$, two-way repeated measures ANOVA). This impact of repeated stress was also observed in rats not exposed to $\mathrm{EPM} \quad$ (control $=10$ neurons, stress $=11$ neurons, $\mathrm{F}_{\text {interaction }}(5,95)=2.65, p=0.028$, two-way repeated measures ANOVA; Supplementary Figure 3D). When subdivided into control and stress nonresponders and stress responders, there was similarly a significant difference of excitability across groups (Figure 6f; $\mathrm{F}_{\text {interaction }}(10,245)=2.82, p=0.003$; control $n=31$ neurons, nonresponders $n=6$ neurons, responders $n=26$ neurons), with significant differences at 200 and $250 \mathrm{pA}$ between stress responders and controls ( $p<0.05$, post hoc Tukey's tests), and at $150-250 \mathrm{pA}$ between stress responders and stress nonresponders $(p<0.05$, post hoc Tukey's tests). Overall, although stress decreased the amplitude of the sAHP of LA neurons (Figure 7e; $p=0.032$, $\mathrm{F}(2,41)=3.75$, one-way ANOVA), it increased sAHP amplitude in stress-nonresponsive rats compared with controls ( $p<0.05$, post hoc Tukey's test), and decreased sAHP amplitude in stress-responsive rats compared with controls ( $p<0.05$, post hoc Tukey's test). Stress significantly affected voltage sag of LA neurons (Figure 7g; $p=0.035$, $\mathrm{F}(2,39)=3.66$, one-way ANOVA), and decreased the amplitude in stress-responsive rats as compared with controls (Figure $7 \mathrm{~g}$ and Table $1 ; p<0.05$, post hoc Tukey's test), whereas there was no significant difference between control and nonresponsive groups ( $p>0.05$, post hoc Tukey's test). This is consistent with a role of sAHP in dampened LA neuronal excitability of stress-nonresponsive rats, and a role of sAHP and voltage sag in the increased LA excitability of stress-responsive rats. There was no significant effect of repeated stress on the amplitude of the mAHP of LA neurons in adult rats (Figure $7 \mathrm{~d} ; p=0.16, \mathrm{~F}(2,41)=2.18$, one-way ANOVA).

To further test the lack of effects of stress on BA neurons of adult rats, correlational analysis was performed. There were no significant associations between adrenal weight and any electrophysiological parameter of BA neurons in adult rats (Figure 8a-c). However, a significant association was 
Table I Membrane Properties of Neurons from the Basal (BA) and Lateral (LA) Nuclei in Adult and Adolescent Rats

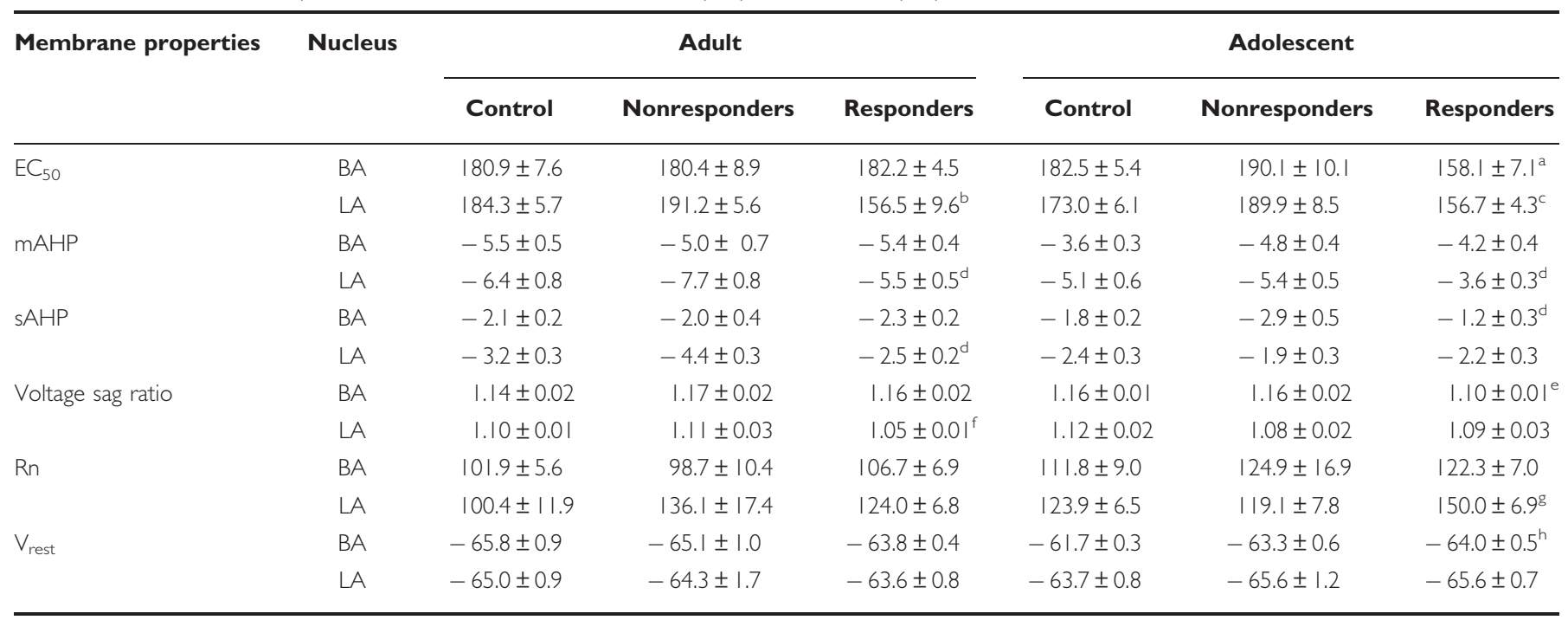

Neurons were from rats exposed to control handling or exposed to repeated restraint stress. Rats that were exposed to repeated stress were categorized as responders or nonresponders based on adrenal gland weight.

${ }^{a}$ One-way ANOVA, $p=0.0 \mathrm{I}, \mathrm{F}(2,32)=5.2$, responders significantly different than controls, responders significantly different than nonresponders, $p<0.05$ in post hoc Tukey's test.

${ }^{b}$ One-way ANOVA, $p=0.01, F(2,42)=5.0$, responders significantly different than controls, responders significantly different than nonresponders, $p<0.05$ in post hoc Tukey's test.

'One-way ANOVA, $p=0.003, F(2,30)=7.3$, responders significantly different than nonresponders, $p<0.05$ in post hoc Tukey's test.

${ }^{\mathrm{d}}$ Significance in one-way ANOVAs. See Results for further detail.

eOne-way ANOVA, $p=0.004, F(2,69)=6.2$, controls significantly different than responders, responders significantly different than nonresponders, $p<0.05$ in post hoc Tukey's test.

${ }^{f}$ One-way ANOVA, $p=0.009, F(2,59)=5.1$, responders significantly different than controls, responders significantly different than nonresponders, $p<0.05$ in post hoc Tukey's test.

:One-way ANOVA, $p=0.009, F(2,50)=5.2$, responders significantly different than control, responders significantly different than nonresponders, $p<0.05$ in post hoc Tukey's test.

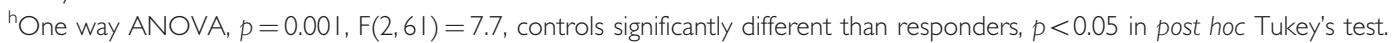

found between adrenal weight and LA neuronal firing $\left(\mathrm{EC}_{50}\right.$; Figure $\left.8 \mathrm{a} ; r^{2}=-0.62, p<0.0001\right)$ and sAHP amplitude (Figure 8c; $r^{2}=0.45, p=0.0028$ ). Exploration in the EPM was significantly associated with firing $\left(r^{2}=0.51, p=0.002\right)$ and sAHP amplitude $\left(r^{2}=-0.41, p=0.017\right)$ of LA neurons in adult rats, but not mAHP amplitude.

\section{DISCUSSION}

Repeated stress often leads to abnormally potent emotive responses, including increased BLA-dependent behaviors. An impact of stress on BLA neurons is likely to contribute to the effects of stress on these behaviors. However, not all individuals display susceptibility to the effects of repeated stress on BLA-modulated affective disorders. The cellular underpinnings of this resilience to stress are not understood. The current study tested whether repeated restraint caused similar effects on BLA neuronal physiology in resilient and vulnerable populations. Resilience and vulnerability were defined based on a well-established biological index of stress, adrenal gland weight (Selye, 1936; Bassett and Cairncross, 1975; Dallman, 1984; Ottenweller et al, 1989; Marquez et al, 2004), and cross checked by EPM and body weight. EPM and body weight are both validated measures of effects of repeated stress in vulnerable rats (Willner et al, 1996; Stone and Quartermain, 1997; Caldji et al, 2000; Maslova et al, 2002; Vyas et al, 2002; Marquez et al, 2004; Vyas and Chattarji, 2004; Weiss et al, 2004; McLaughlin et al, 2007; Pohl et al, 2007; Zhang and Rosenkranz, 2012), further validating the subdivision of populations.

Two primary goals of this study were to compare the effects of repeated stress in adult and adolescent rats, and to compare the effects in the BA and LA nuclei, with an emphasis on the mAHP and sAHP. We found that repeated stress exerted different actions across age and BLA nucleus that implicate the sAHP as a target for the effects of stress on BLA-dependent behaviors in adult rats, and a potential protective role for the sAHP in resilient rats.

A different pattern emerged in adolescent rats. After repeated restraint, neurons of the both BA and LA displayed increased excitability. However, in adolescent rats, the mAHP in LA neurons, instead of the sAHP, may be the more important target for the effects of repeated stress on BLA-dependent behaviors. In contrast, resilience to the effects of stress may be related to increased sAHP of BA neurons in adolescent rats. These changes of AHP amplitude can contribute to the effects of repeated stress on neuronal excitability. 

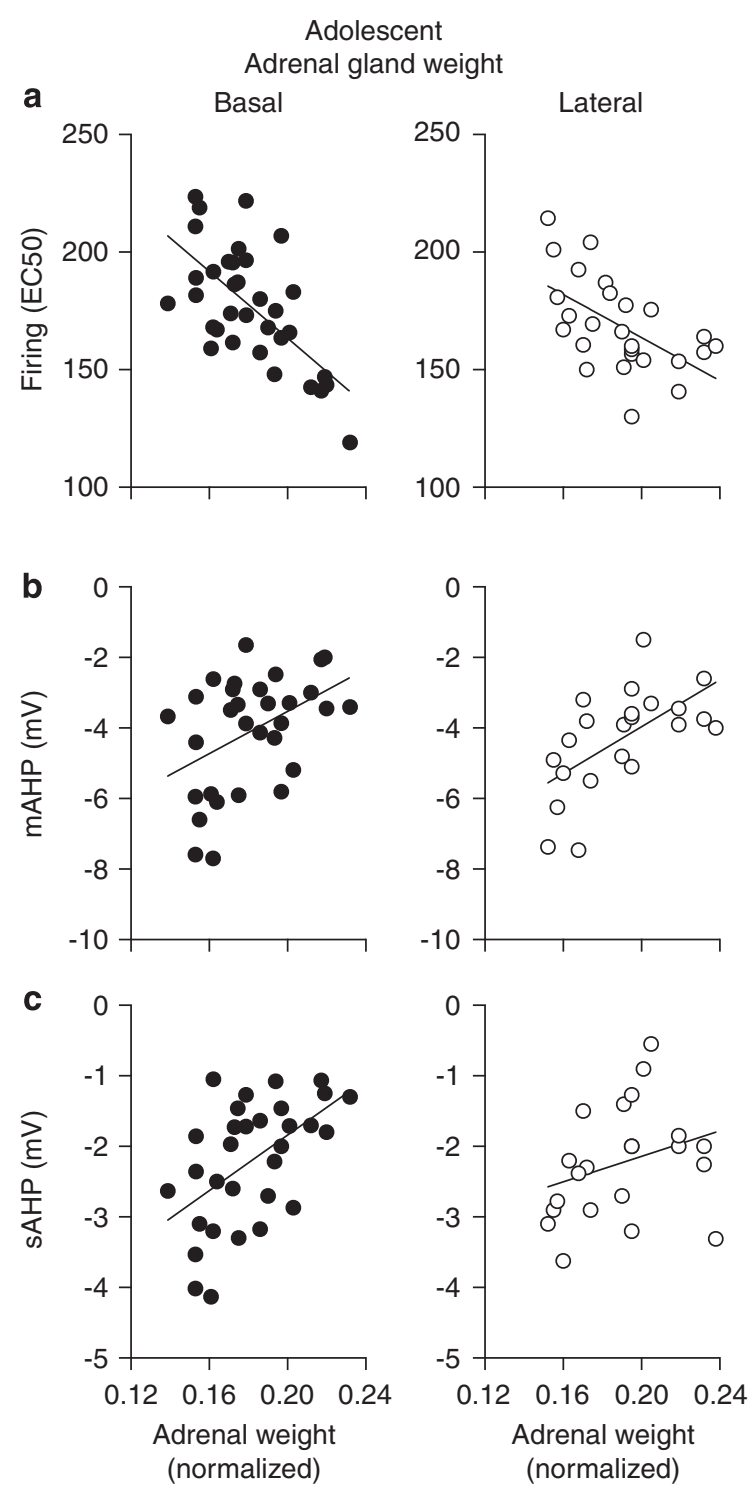

Figure 5 Correlations between adrenal gland weight, BLA neuronal firing, and AHP amplitudes in adolescent rats. Adrenal gland weight of rats in all groups was correlated with electrophysiological parameters of BA and LA neurons. (a) The EC 50 of the excitability (current intensity-action potential firing curve) was calculated. There was a significant correlation between adrenal gland weight and the $E_{50}$ of $B A$ neurons and $L A$ neurons. (b) Adrenal gland weight was significantly correlated with the mAHP amplitude in LA, but not BA neurons. (c) In contrast, adrenal gland weight was significantly correlated with sAHP amplitude in BA but not LA neurons.

Increased sAHP of BA neurons in adolescents and increased mAHP of LA neurons in adults were associated with resilience. The faster decaying $\mathrm{mAHP}(50-150 \mathrm{~ms})$ and slowly decaying sAHP (often 1-2 s; Rainnie et al, 1993) likely play distinct roles in modulation of BLA excitability and synaptic integration. The apamin-sensitive mAHP (probably comprising SK2/SK3) regulates spike frequency adaptation in adult LA neurons (Chen and Lang, 2003) and young BA neurons (P21-28; Power and Sah, 2008), but does not appear to strongly modulate synaptic inputs (Power et al, 2011). In contrast, the sAHP contributes to spike frequency adaptation of LA neurons and dampens excitatory

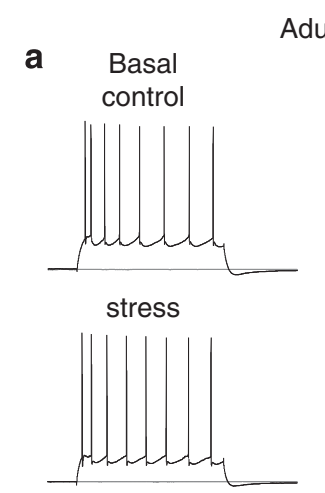

Adult
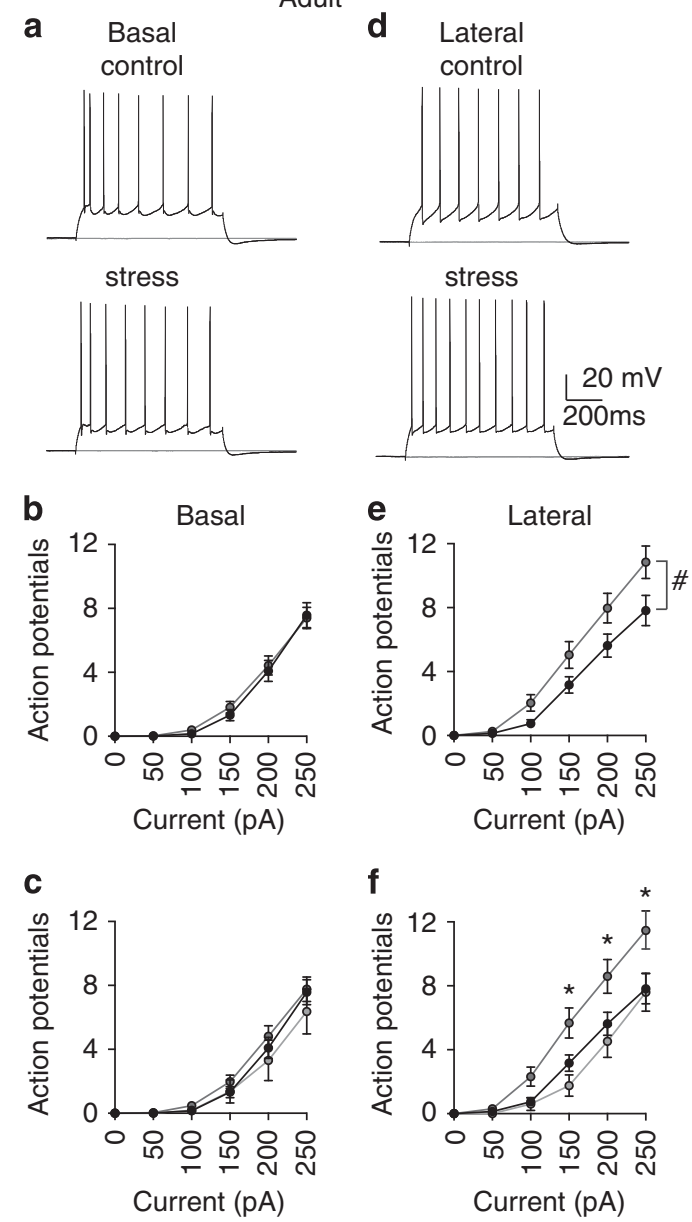

Figure 6 Repeated restraint increases the excitability of BA but not LA neurons in adult rats. (a) Repeated stress had no obvious effect on the excitability of BA neurons in adult rats. (b) There was no significant effect of repeated stress on $B A$ neuronal excitability at any of the current intensities examined. (c) Even when BA neurons were separated into stressresponsive and stress-nonresponsive groups, no significant difference in BA neuronal excitability emerged. (d) Repeated stress increased excitability of LA neurons in adult rats. (e) The increased excitability of LA neurons was observed over a range of current steps. (f) Stress-responsive rats displayed significantly greater LA neuronal excitability than nonresponsive and control rats. ${ }^{\#} p<0.05$ significant interaction in two-way repeated measures ANOVA. ${ }^{*} p<0.05$ between stress-responsive and stress-nonresponsive rats, and between stress-responsive and control rats after two-way repeated measures ANOVA followed by post hoc Tukey's test.

synaptic input (Chen and Lang, 2003; Faber et al, 2005). The sAHP appears to be present along the dendrite of BA neurons in young rats (P21-28), can be activated by synaptic input to LA neurons (Lang and Pare, 1997; Power et al, 2011), and has a significant contribution to dendritic propagation of synaptic inputs to the soma (Power et al, 2011). Therefore, the increased sAHP in adolescent resilient rats not only reduces membrane excitability, but likely also reduces excitatory drive from glutamatergic inputs. In contrast, the increased mAHP of adult resilient rats is less likely to influence the integration of excitatory inputs. It is not known what factors lead to selective changes of mAHP compared with sAHP in these populations of neurons. Several factors have been 
demonstrated to modulate the expression of SK channels that contribute to the mAHPs and sAHPs. Activation of $\beta$ adrenergic receptors (Faber et al, 2008), activation of PKA (Ren et al, 2006), and neuronal activity (Lin et al, 2010) all modify the expression of SK channel subunits. Perhaps, the differences in the effects of repeated stress on these factors in adult and adolescent neurons between the BA and LA contribute to these age- and nucleus-specific differences.

Genetic and epigenetic (Francis et al, 1999; Weaver et al, 2002; Rijsdijk et al, 2003) factors can contribute to resilience. These include polymorphisms or expression of BDNF (Krishnan et al, 2007), GABRA2 (Nelson et al, 2009),

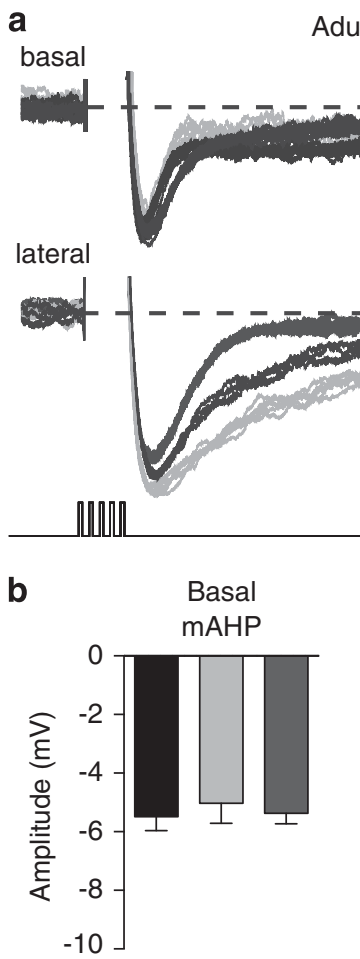

Adult
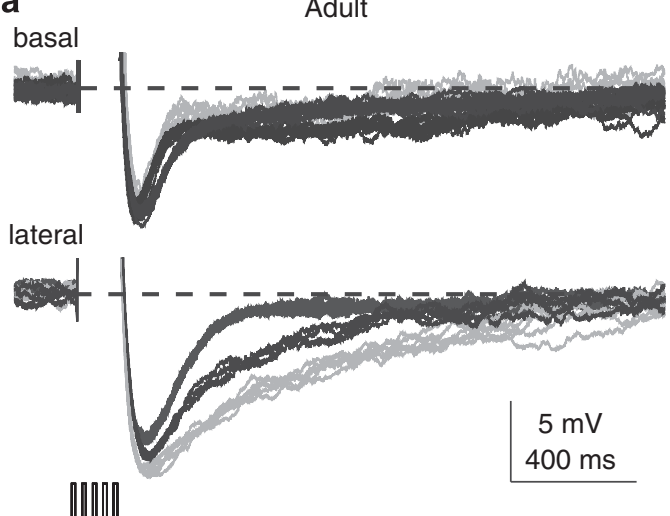

b

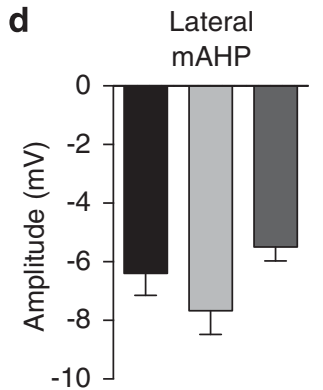

C
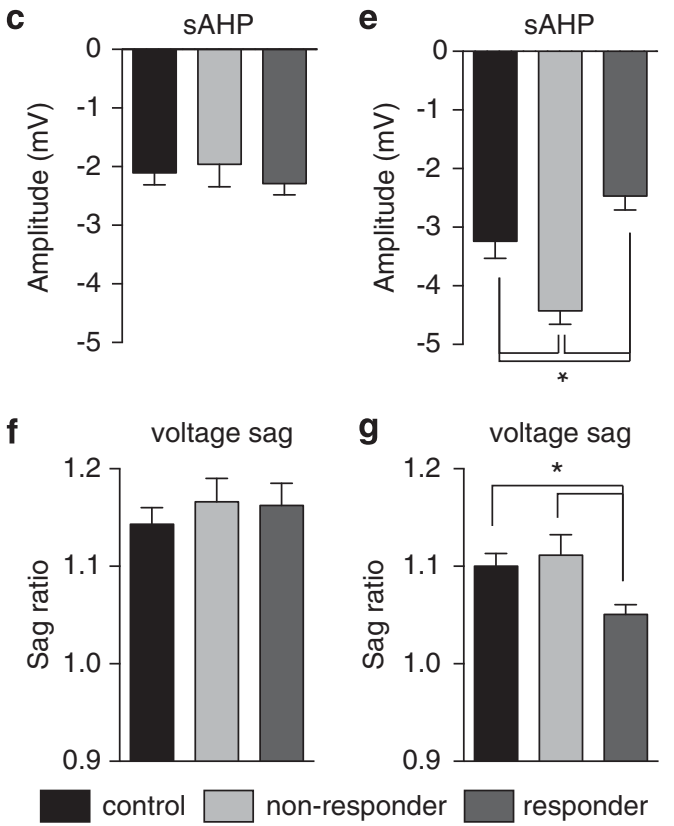

5-HT1A receptors, dopamine or serotonin transporters (Segman et al, 2002; Kilpatrick et al, 2007; Stein et al, 2009; Wald et al, 2013), catechol-O-methyl transferase (COMT; Jabbi et al, 2007; Kolassa et al, 2010), glucocorticoid receptors and factors that modulate them such as FK506-binding protein (FKBP5; Binder et al, 2008; Derijk and de Kloet, 2008; McGowan et al, 2009; Sarapas et al, 2011), and methylation of corticotrophin-releasing factor (CRF) receptor DNA (Elliott et al, 2010). Several genetically distinct rodent lines are differentially resistant/vulnerable to the effects of stress (Razzoli et al, 2011; Savignac et al, 2011; Camp et al, 2012; Fuchsl et al, 2014). The amygdala circuits that regulate fear and anxiety are hypothesized to be an important target of some of these genetic differences (Hariri et al, 2002; Smolka et al, 2005; Jovanovic and Ressler, 2010; Mozhui et al, 2010; Alexander et al, 2012; Hermann et al, 2012; White et al, 2012; Rogers et al, 2013; Volman et al, 2013). Many of these transmitter systems listed above directly or indirectly modulate the same signaling cascades that modify SK channel function (Pedarzani and Storm, 1995; Pedarzani et al, 1998; Lee et al, 2003; Bildl et al, 2004; Ren et al, 2006; Maingret et al, 2008), leading to changes in the excitability of amygdala neurons.

These results are consistent with the different effects of repeated stress on BLA neurons of resilient and vulnerable rats. Alternatively, it is possible that the differences in neuronal physiology between resilient and vulnerable rat existed before stress. However, a previous study that examined the morphology of BA neurons in high and low stress-responsive rodents did not find any difference (Pillai et al, 2012), whereas Adamec et al (2012) found significant dendritic hypertrophy in anxious control rats, but no further effect of stress. Furthermore, neuronal excitability of control rats was significantly less than stressed rats, before subdivision into resilient and vulnerable, indicating that stress had an overall impact on membrane properties. Although this finding is not consistent with preexistent differences between control and stress groups as the source of the measured differences after stress/control handling, it does not rule out the possibility that other preexistent differences in BLA neuronal physiology contribute to resilience or vulnerability. For instance, stress-responsive

Figure 7 Effects of repeated restraint on AHP of BLA neurons in adult rats. (a) AHPs of BA neurons from adult rats (top), evoked by a burst of action potentials, were similar in control (black), nonresponsive (light gray), and responsive (dark gray) groups. However, the sAHP of LA neurons (bottom) was noticeably smaller in stress-responsive rats (dark gray) and larger in nonresponsive rats (light gray) as compared with control rats (black). (b) In BA neurons, there was no significant difference in mAHP amplitude between control, nonresponsive, and responsive groups. (c) Similarly, there was no significant difference in SAHP amplitude of BA neurons between control, nonresponsive, and responsive groups. (d) In LA neurons, there was no significant difference in mAHP amplitude between control, nonresponsive, and responsive groups. (e) However, there was a significantly greater sAHP amplitude in LA neurons from nonresponsive rats, and a significantly smaller sAHP amplitude in LA neurons from responsive rats. (f) In BA neurons, there was no significant effect of repeated stress on voltage sag ratio. (g) However, in LA neurons there was a significantly smaller voltage sag ratio in responders after repeated stress. *p $<0.05$ after one-way ANOVA followed by post hoc Tukey's test. The colour reproduction of this figure is available on the html full text version of the manuscript. 
Adult
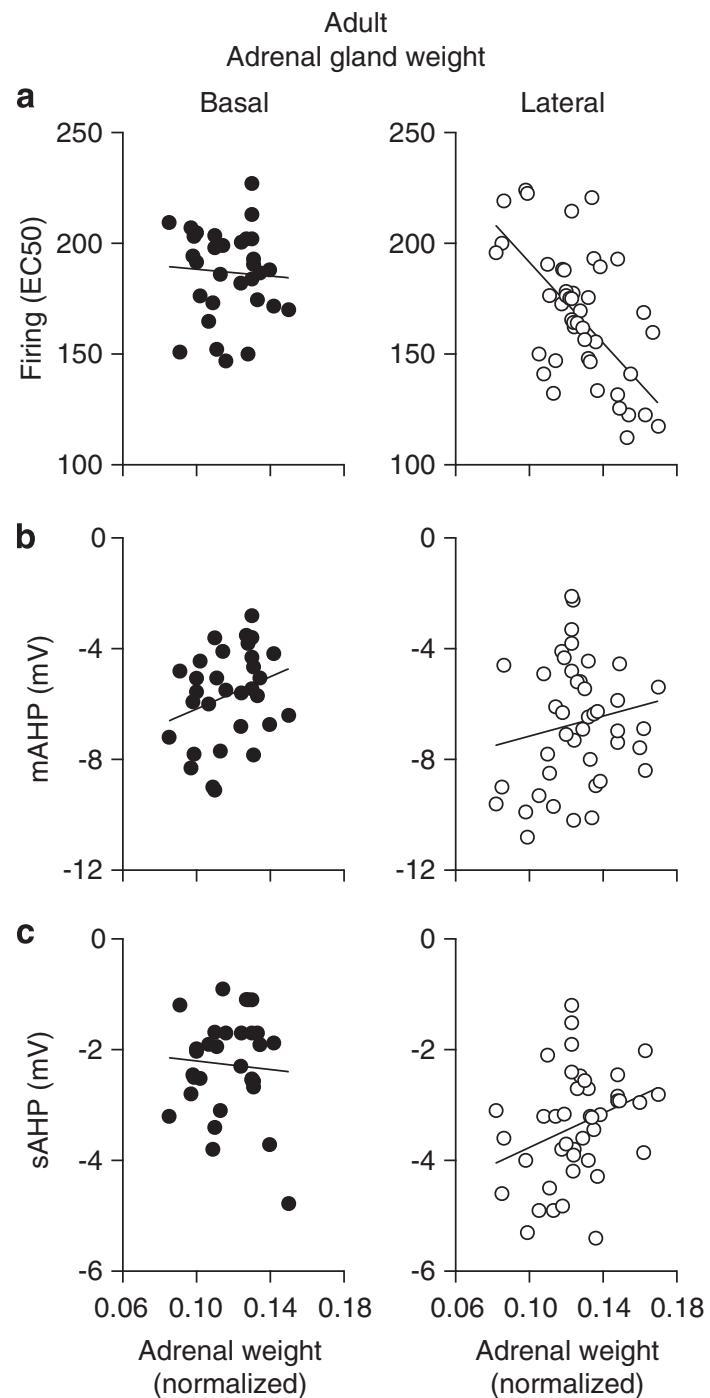

Figure 8 Correlations between adrenal gland weight, BLA firing, and neuronal AHP amplitudes in adult rats. Adrenal gland weight of rats in all groups was correlated with electrophysiological parameters of BA and LA neurons. (a) The $\mathrm{EC}_{50}$ of the excitability (current intensity-action potential firing curve) was calculated. There was a significant correlation between adrenal gland weight and the $\mathrm{EC}_{50}$ of LA neurons, and no correlation between adrenal gland weight and $\mathrm{EC}_{50}$ of BA neurons. (b) Adrenal gland weight was not significantly correlated with the mAHP amplitude in LA or BA neurons. (c) In contrast, adrenal gland weight was significantly correlated with sAHP amplitude in LA but not BA neurons.

mice display greater NMDA receptor responses (Mozhui et al, 2010) and dendritic hypertrophy (Mitra et al, 2009), and rats can be made resilient to the effects of stress by modulation of h channels (Giesbrecht et al, 2010). One aspect of the novelty of the current findings is that resiliency and vulnerability to stress display signatures in the physiology of BA and LA neurons, and these signatures are correlated with effects of stress on anxiety-like behavior.

$\mathrm{K}_{\mathrm{Ca}}$ channels play an important role in the modulation of BLA firing and synaptic integration (Rainnie et al, 1993; Chen and Lang, 2003; Faber et al, 2005; Power and Sah, 2008). Furthermore, the AHP induced by SK channels are acutely modulated by stress hormones (Duvarci and Pare, 2007), and have been shown to underlie some of the effects of repeated stress on hyperexcitability of LA neurons (Rosenkranz et al, 2010). However, the effects of repeated stress on $\mathrm{K}_{\mathrm{Ca}}$ channel function had not been contrasted between BA and LA neurons, or between adults and adolescents. The present studies indicate that AHPs are modified by repeated stress in a bidirectional manner; AHPs in LA neurons are reduced in stress-vulnerable adult and adolescent rats but AHPs in BA neurons are increased in stress-resilient adolescent rats and in LA neurons in stress-resilient adult rats. However, the data indicate that SK channels are not the only targets of repeated stress. Repeated stress reduced the voltage- sag, indicative of $h$ channel function, in adult LA neurons and adolescent BA neurons. Changes in voltage sag may contribute to the effects of stress on neuronal excitability if the neuron is resting at a membrane potential near its activation range. However, the voltage at which $\mathrm{h}$ channels become substantially active in BLA neurons may be more hyperpolarized than the resting membrane potential (Giesbrecht et al, 2010) that itself may be more depolarized in vivo, such that $\mathrm{h}$ channels contribute little conductance at rest, and only minimally contribute to somatic excitability. They may play a role in dampening dendritic integration of inputs and dendritic excitability, as the activation of $h$ channels is shifted toward the depolarized direction in some cortical-like structures (Magee, 1998). Alternatively, a decrease of $\mathrm{h}$ channel function may hyperpolarize the resting membrane potential by a small degree, and compete against other factors that increase excitability of BLA neurons (Giesbrecht et al, 2010).

Repeated administration of ACTH or repeated stress leads to hypertrophy of the adrenal gland (Dallman, 1984; UlrichLai et al, 2006). Adrenal gland hypertrophy is associated with increased synthesis of glucocorticoids (Treiman and Levine, 1969; Mazzocchi et al, 1986). As such, adrenal gland weight can be a reliable measure for the cumulative impact of repeated stress (Armario, 2006). The link between adrenal gland weight and BLA neuronal function in these studies is not clear. A hyperresponsive hypothalamicpituitary-adrenal axis upon repeated stress will produce higher levels of circulating corticosterone in response to a range of stimuli. This increase of corticosterone itself may contribute to the effects of repeated stress observed here, as well as contribute to differences between resilient and vulnerable populations. Previous studies in rats demonstrate acute effects of corticosterone on BLA pyramidal neurons, resulting in enhanced excitability. Corticosterone increases the excitability of BA neurons and decreases mAHP amplitudes (3-5-week-old rats; Duvarci and Pare, 2007). However, the amplitude of the sAHP does not appear to be affected by single application of corticosterone (Liebmann et al, 2008). Corticosterone can also increase synaptic release of glutamate in the BLA in a rapid mineralocorticoid-dependent manner while decreasing glutamate release in a slow, glucocorticoid receptor-dependent manner (Karst et al, 2010). Application of the stress hormone CRF also increases membrane excitability of BA neurons (3-8-week-old rats; Giesbrecht et al, 2010), increases responses to afferents (adult rats; Sandi et al, 2008), and reduces their sAHPs (125-150 g, 4-6-week-old rats; Rainnie et al, 1992). Although these studies parallel many of the changes observed in the current study, and can 
shed light on possible intermediaries of the effects of stress on BLA neuronal physiology, there are some significant differences. These studies examined acute effects of stress hormones, whereas the current study utilized repeated stress. Our previous studies indicate that a single $20 \mathrm{~min}$ restraint stress does not significantly affect the excitability of LA neurons in adult rats (Rosenkranz et al, 2010) or the firing of BA or LA neurons in adult or adolescent rats (Zhang and Rosenkranz, 2012). However, a previous study in adult mice found that a single $1 \mathrm{~h}$ restraint is sufficient to induce increased excitability of LA neurons (Guo et al, 2012) and increases synaptic excitability in BA neurons of adult rats (Rodriguez Manzanares et al, 2005). A short course of repeated stress (3 days) in young rats (P22) led to a deficit in GABAergic inhibition of BA neurons (Braga et al, 2004). However, that is not likely to contribute to the effects observed here because GABAergic inputs were pharmacologically blocked in the current study. More directly parallel to the current study, repeated infusion of a CRF agonist into the BA did not significantly affect neuronal excitability, but could still lead to increased activity of BA neurons via hyperexcitability of the BA network (adult rats; Rainnie et al, 2004), repeated stress did not change the membrane properties of BA neurons in adult rats (Hubert et al, 2013), and repeated stress increased the response of BA neurons to excitatory inputs (Sandi et al, 2008), increased NMDA responses (Mozhui et al, 2010), and slowly increased synaptic glutamate receptors (Hubert et al, 2013). Similarly, in the current study, repeated restraint also did not increase the excitability of BA neurons, but perhaps increases excitatory drive of BA neurons (Padival et al, 2013a), leading to increased firing in adult rats (Zhang and Rosenkranz, 2012). One component of the novelty of the current findings is a demonstration of differences in the effects of stress on BA and LA neurons, and potential mechanisms for these differences.

Stress exposure during development has long-lasting effects on behavior, for instance, elevated anxiety and fear behavior as well as poorer performance in spatial learning (Avital et al, 2006; Vidal et al, 2007; Lukkes et al, 2009). A recent study found that repeated restraint stress exerts different effects on the firing of BA and LA neurons in adult and adolescent rats (Zhang and Rosenkranz, 2012). The current study builds upon this by demonstrating a potential mechanism for differences in the effects of stress on firing of BA and LA neurons across age, with a shift in the BLA signature of resilience and vulnerability in adolescents and adults. The LA is implicated in acquisition and expression of cued fear conditioning (Nader et al, 2001; Rodrigues et al, 2001; Calandreau et al, 2005). Both adult and adolescent rats display increased excitability of LA neurons (observed here) in parallel with increased conditioned freezing after repeated restraint stress (Zhang and Rosenkranz, 2013). In contrast, fear extinction relies heavily upon the BA (Herry et al, 2008; Zimmerman and Maren, 2010; Amano et al, 2011; Davis and Bauer, 2012; however, pretraining lesions of BA do not impair extinction, Anglada-Figueroa and Quirk, 2005). Fear extinction after repeated restraint stress was impaired in adolescent rats, but not adult rats (Zhang and Rosenkranz, 2013). In parallel, we observed that repeated stress increased the excitability of the BA in adolescents but not adult rats. The divergent effects of repeated stress in BLA nuclei between adult and adolescent rats may be a substrate for the distinct effects of repeated stress on fear behavior in adult and adolescent rats.

\section{CONCLUSION}

Our data demonstrate an age-dependent shift in the effects of repeated stress from the BA and LA during adolescence to the LA in adulthood. There was also an age-dependent shift in the correlates of resilience: increased sAHP of BA neurons in adolescents to increased mAHP of LA neurons in adults. The higher excitability of BA or LA neurons is expected to result in a greater output, and thereby exert a greater influence on affective behavior. This can contribute to the differences in the symptomatology of stress-induced anxiety and depressive disorders, and can provide distinct targets to improve stress resilience in adults or adolescents.

\section{FUNDING AND DISCLOSURE}

The authors declare no conflict of interest. Repeated restraint stress, EPM, and histology were done by AH; the study was designed by JAR; in vitro recordings were done by JAR and $\mathrm{AH}$; the manuscript was written by JAR and $\mathrm{AH}$. Both authors have approved the final article.

\section{ACKNOWLEDGEMENTS}

We thank Mallika Padival for technical assistance. This work was funded by Grant MH84970 from the National Institute of Mental Health and Rosalind Franklin University of Medicine and Science.

\section{REFERENCES}

Adamec R, Hebert M, Blundell J, Mervis RF (2012). Dendritic morphology of amygdala and hippocampal neurons in more and less predator stress responsive rats and more and less spontaneously anxious handled controls. Behav Brain Res 226: 133-146.

Alexander N, Klucken T, Koppe G, Osinsky R, Walter B, Vaitl D et al (2012). Interaction of the serotonin transporter-linked polymorphic region and environmental adversity: increased amygdala-hypothalamus connectivity as a potential mechanism linking neural and endocrine hyperreactivity. Biol Psychiatry 72: 49-56.

Alim TN, Feder A, Graves RE, Wang Y, Weaver J, Westphal M et al (2008). Trauma, resilience, and recovery in a high-risk AfricanAmerican population. Am J Psychiatry 165: 1566-1575.

Allen MT, Matthews KA (1997). Hemodynamic responses to laboratory stressors in children and adolescents: the influences of age, race, and gender. Psychophysiology 34: 329-339.

Amano T, Duvarci S, Popa D, Pare D (2011). The fear circuit revisited: contributions of the basal amygdala nuclei to conditioned fear. J Neurosci 31: 15481-15489.

Anglada-Figueroa D, Quirk GJ (2005). Lesions of the basal amygdala block expression of conditioned fear but not extinction. J Neurosci 25: 9680-9685.

Armario A (2006). The hypothalamic-pituitary-adrenal axis: what can it tell us about stressors? CNS Neurol Disord Drug Targets 5: 485-501.

Atchley D, Hankosky ER, Gasparotto K, Rosenkranz JA (2012). Pharmacological enhancement of calcium-activated potassium 
channel function reduces the effects of repeated stress on fear memory. Behav Brain Res 232: 37-43.

Avital A, Ram E, Maayan R, Weizman A, Richter-Levin G (2006). Effects of early-life stress on behavior and neurosteroid levels in the rat hypothalamus and entorhinal cortex. Brain Res Bull 68: 419-424.

Bassett JR, Cairncross KD (1975). Morphological changes induced in rats following prolonged exposure to stress. Pharmacol Biochem Behav 3: 411-420.

Bergstrom A, Jayatissa MN, Thykjaer T, Wiborg O (2007). Molecular pathways associated with stress resilience and drug resistance in the chronic mild stress rat model of depression: a gene expression study. J Mol Neurosci 33: 201-215.

Bildl W, Strassmaier T, Thurm H, Andersen J, Eble S, Oliver D et al (2004). Protein kinase CK2 is coassembled with small conductance $\mathrm{Ca}(2+)$-activated $\mathrm{K}+$ channels and regulates channel gating. Neuron 43: 847-858.

Binder EB, Bradley RG, Liu W, Epstein MP, Deveau TC, Mercer KB et al (2008). Association of FKBP5 polymorphisms and childhood abuse with risk of posttraumatic stress disorder symptoms in adults. JAMA 299: 1291-1305.

Blugeot A, Rivat C, Bouvier E, Molet J, Mouchard A, Zeau B et al (2011). Vulnerability to depression: from brain neuroplasticity to identification of biomarkers. J Neurosci 31: 12889-12899.

Braga MF, Aroniadou-Anderjaska V, Manion ST, Hough CJ, Li H (2004). Stress impairs alpha(1A) adrenoceptor-mediated noradrenergic facilitation of GABAergic transmission in the basolateral amygdala. Neuropsychopharmacology 29: 45-58.

Buchanan CM, Eccles JS, Becker JB (1992). Are adolescents the victims of raging hormones: evidence for activational effects of hormones on moods and behavior at adolescence. Psychol Bull 111: 62-107.

Calandreau L, Desmedt A, Decorte L, Jaffard R (2005). A different recruitment of the lateral and basolateral amygdala promotes contextual or elemental conditioned association in Pavlovian fear conditioning. Learn Mem 12: 383-388.

Caldji C, Diorio J, Meaney MJ (2000). Variations in maternal care in infancy regulate the development of stress reactivity. Biol Psychiatry 48: 1164-1174.

Camp MC, Macpherson KP, Lederle L, Graybeal C, Gaburro S, Debrouse LM et al (2012). Genetic strain differences in learned fear inhibition associated with variation in neuroendocrine, autonomic, and amygdala dendritic phenotypes. Neuropsychopharmacology 37: 1534-1547.

Castro JE, Diessler S, Varea E, Marquez C, Larsen $\mathrm{MH}$, Cordero MI et al (2012). Personality traits in rats predict vulnerability and resilience to developing stress-induced depression-like behaviors, HPA axis hyper-reactivity and brain changes in pERK1/2 activity. Psychoneuroendocrinology 37: 1209-1223.

Chareyron LJ, Lavenex PB, Lavenex P (2012). Postnatal development of the amygdala: a stereological study in rats. J Comp Neurol 520: 3745-3763.

Chen JC, Lang EJ (2003). Inhibitory control of rat lateral amygdaloid projection cells. Neuroscience 121: 155-166.

Clermont Y, Perey B (1957). Quantitative study of the cell population of the seminiferous tubules in immature rats. Am J Anat 100: 241-267.

Compas BE, Orosan PG, Grant KE (1993). Adolescent stress and coping: implications for psychopathology during adolescence. J Adolesc 16: 331-349.

Conrad CD, LeDoux JE, Magarinos AM, McEwen BS (1999). Repeated restraint stress facilitates fear conditioning independently of causing hippocampal CA3 dendritic atrophy. Behav Neurosci 113: 902-913.

Dallman MF (1984). Control of adrenocortical growth in vivo. Endocr Res 10: 213-242.
Davis SE, Bauer EP (2012). L-type voltage-gated calcium channels in the basolateral amygdala are necessary for fear extinction. I Neurosci 32: 13582-13586.

Derijk RH, de Kloet ER (2008). Corticosteroid receptor polymorphisms: determinants of vulnerability and resilience. Eur $\mathrm{J}$ Pharmacol 583: 303-311.

Doremus TL, Brunell SC, Varlinskaya EI, Spear LP (2003). Anxiogenic effects during withdrawal from acute ethanol in adolescent and adult rats. Pharmacol Biochem Behav 75: 411-418.

Doremus TL, Varlinskaya EI, Spear LP (2004). Age-related differences in elevated plus maze behavior between adolescent and adult rats. Ann NY Acad Sci 1021: 427-430.

Duvarci S, Pare D (2007). Glucocorticoids enhance the excitability of principal basolateral amygdala neurons. J Neurosci 27: 4482-4491.

Ehrlich DE, Ryan SJ, Hazra R, Guo JD, Rainnie DG (2013). Postnatal maturation of GABAergic transmission in the rat basolateral amygdala. J Neurophysiol 110: 926-941.

Ehrlich DE, Ryan SJ, Rainnie DG (2012). Postnatal development of electrophysiological properties of principal neurons in the rat basolateral amygdala. J Physiol 590: 4819-4838.

Einon DF, Morgan MJ (1977). A critical period for social isolation in the rat. Dev Psychobiol 10: 123-132.

Elliott E, Ezra-Nevo G, Regev L, Neufeld-Cohen A, Chen A (2010). Resilience to social stress coincides with functional DNA methylation of the Crf gene in adult mice. Nat Neurosci 13: 1351-1353.

Faber ES, Callister RJ, Sah P (2001). Morphological and electrophysiological properties of principal neurons in the rat lateral amygdala in vitro. J Neurophysiol 85: 714-723.

Faber ES, Delaney AJ, Power JM, Sedlak PL, Crane JW, Sah P (2008). Modulation of SK channel trafficking by beta adrenoceptors enhances excitatory synaptic transmission and plasticity in the amygdala. J Neurosci 28: 10803-10813.

Faber ES, Delaney AJ, Sah P (2005). SK channels regulate excitatory synaptic transmission and plasticity in the lateral amygdala. Nat Neurosci 8: 635-641.

Feder A, Nestler EJ, Charney DS (2009). Psychobiology and molecular genetics of resilience. Nat Rev Neurosci 10: 446-457.

Francis D, Diorio J, Liu D, Meaney MJ (1999). Nongenomic transmission across generations of maternal behavior and stress responses in the rat. Science 286: 1155-1158.

Fuchsl AM, Neumann ID, Reber SO (2014). Stress resilience: a lowanxiety genotype protects male mice from the consequences of chronic psychosocial stress. Endocrinology 155: 117-126.

Giesbrecht CJ, Mackay JP, Silveira HB, Urban JH, Colmers WF (2010). Countervailing modulation of Ih by neuropeptide Y and corticotrophin-releasing factor in basolateral amygdala as a possible mechanism for their effects on stress-related behaviors. J Neurosci 30: 16970-16982.

Grant KE, Compas BE, Thurm AE, McMahon SD, Gipson PY, Campbell AJ et al (2006). Stressors and child and adolescent psychopathology: evidence of moderating and mediating effects. Clin Psychol Rev 26: 257-283.

Guo YY, Liu SB, Cui GB, Ma L, Feng B, Xing JH et al (2012). Acute stress induces down-regulation of large-conductance $\mathrm{Ca} 2+-$ activated potassium channels in the lateral amygdala. J Physiol 590: 875-886.

Hariri AR, Mattay VS, Tessitore A, Kolachana B, Fera F, Goldman $\mathrm{D}$ et al (2002). Serotonin transporter genetic variation and the response of the human amygdala. Science 297: 400-403.

Hascoet M, Colombel MC, Bourin M (1999). Influence of age on behavioural response in the light/dark paradigm. Physiol Behav 66: 567-570.

Heim C, Nemeroff CB (2001). The role of childhood trauma in the neurobiology of mood and anxiety disorders: preclinical and clinical studies. Biol Psychiatry 49: 1023-1039. 
Hermann A, Kupper Y, Schmitz A, Walter B, Vaitl D, Hennig J et al (2012). Functional gene polymorphisms in the serotonin system and traumatic life events modulate the neural basis of fear acquisition and extinction. PLoS One 7: e44352.

Herry C, Ciocchi S, Senn V, Demmou L, Muller C, Luthi A (2008). Switching on and off fear by distinct neuronal circuits. Nature 454: 600-606.

Hetzel A, Meredith GE, Rademacher DJ, Rosenkranz JA (2012). Effect of amphetamine place conditioning on excitatory synaptic events in the basolateral amygdala ex vivo. Neuroscience 206: 7-16.

Hubert GW, Li C, Rainnie DG, Muly EC (2013). Effects of stress on AMPA receptor distribution and function in the basolateral amygdala. Brain Struct Funct; epub ahead of print 5 May 2013; doi:10.1007/s00429-013-0557-z.

Jabbi M, Korf J, Kema IP, Hartman C, van der Pompe G, Minderaa RB et al (2007). Convergent genetic modulation of the endocrine stress response involves polymorphic variations of 5-HTT, COMT and MAOA. Mol Psychiatry 12: 483-490.

Jovanovic T, Ressler KJ (2010). How the neurocircuitry and genetics of fear inhibition may inform our understanding of PTSD. Am J Psychiatry 167: 648-662.

Kabbaj M (2004). Neurobiological bases of individual differences in emotional and stress responsiveness: high responders-low responders model. Arch Neurol 61: 1009-1012.

Karst H, Berger S, Erdmann G, Schutz G, Joels M (2010). Metaplasticity of amygdalar responses to the stress hormone corticosterone. Proc Natl Acad Sci USA 107: 14449-14454.

Kilpatrick DG, Koenen KC, Ruggiero KJ, Acierno R, Galea S, Resnick HS et al (2007). The serotonin transporter genotype and social support and moderation of posttraumatic stress disorder and depression in hurricane-exposed adults. Am J Psychiatry 164: 1693-1699.

Kolassa IT, Kolassa S, Ertl V, Papassotiropoulos A, De Quervain DJ (2010). The risk of posttraumatic stress disorder after trauma depends on traumatic load and the catechol-o-methyltransferase Val(158)Met polymorphism. Biol Psychiatry 67: 304-308.

Korenbrot CC, Huhtaniemi IT, Weiner RI (1977). Preputial separation as an external sign of pubertal development in the male rat. Biol Reprod 17: 298-303.

Krishnan V, Han MH, Graham DL, Berton O, Renthal W, Russo SJ et al (2007). Molecular adaptations underlying susceptibility and resistance to social defeat in brain reward regions. Cell 131: 391-404.

Lang EJ, Pare D (1997). Synaptic and synaptically activated intrinsic conductances underlie inhibitory potentials in cat lateral amygdaloid projection neurons in vivo. J Neurophysiol 77: 353-363.

Lee WS, Ngo-Anh TJ, Bruening-Wright A, Maylie J, Adelman JP (2003). Small conductance Ca2 +-activated K + channels and calmodulin: cell surface expression and gating. J Biol Chem 278: 25940-25946.

Liebmann L, Karst H, Sidiropoulou K, van Gemert N, Meijer OC, Poirazi P et al (2008). Differential effects of corticosterone on the slow afterhyperpolarization in the basolateral amygdala and CA1 region: possible role of calcium channel subunits. I Neurophysiol 99: 958-968.

Lin MT, Lujan R, Watanabe M, Frerking M, Maylie J, Adelman JP (2010). Coupled activity-dependent trafficking of synaptic SK2 channels and AMPA receptors. J Neurosci 30: $11726-11734$.

Luine VN, Beck KD, Bowman RE, Frankfurt M, Maclusky NJ (2007). Chronic stress and neural function: accounting for sex and age. J Neuroendocrinol 19: 743-751.

Lukkes JL, Mokin MV, Scholl JL, Forster GL (2009). Adult rats exposed to early-life social isolation exhibit increased anxiety and conditioned fear behavior, and altered hormonal stress responses. Horm Behav 55: 248-256.
Magee JC (1998). Dendritic hyperpolarization-activated currents modify the integrative properties of hippocampal CA1 pyramidal neurons. J Neurosci 18: 7613-7624.

Maingret F, Coste B, Hao J, Giamarchi A, Allen D, Crest M et al (2008). Neurotransmitter modulation of small-conductance $\mathrm{Ca} 2+$-activated $\mathrm{K}+$ channels by regulation of $\mathrm{Ca} 2+$ gating. Neuron 59: 439-449.

Marquez C, Nadal R, Armario A (2004). The hypothalamicpituitary-adrenal and glucose responses to daily repeated immobilisation stress in rats: individual differences. Neuroscience 123: 601-612.

Maslova LN, Bulygina VV, Markel AL (2002). Chronic stress during prepubertal development: immediate and long-lasting effects on arterial blood pressure and anxiety-related behavior. Psychoneuroendocrinology 27: 549-561.

Mazzocchi G, Malendowicz LK, Rebuffat P, Robba C, Gottardo G, Nussdorfer GG (1986). Short- and long-term effects of ACTH on the adrenal zona glomerulosa of the rat. A coupled stereological and enzymological study. Cell Tissue Res 243: 303-310.

McDonald AJ (1982). Neurons of the lateral and basolateral amygdaloid nuclei: a Golgi study in the rat. J Comp Neurol 212: 293-312.

McDonald AJ (1984). Neuronal organization of the lateral and basolateral amygdaloid nuclei in the rat. J Comp Neurol 222: 589-606.

McGowan PO, Sasaki A, D’Alessio AC, Dymov S, Labonte B, Szyf M et al (2009). Epigenetic regulation of the glucocorticoid receptor in human brain associates with childhood abuse. Nat Neurosci 12: $342-348$

McLaughlin KJ, Gomez JL, Baran SE, Conrad CD (2007). The effects of chronic stress on hippocampal morphology and function: an evaluation of chronic restraint paradigms. Brain Res 1161: 56-64.

Meaney MJ, Aitken DH, Bodnoff SR, Iny LJ, Sapolsky RM (1985). The effects of postnatal handling on the development of the glucocorticoid receptor systems and stress recovery in the rat. Prog Neuropsychopharmacol Biol Psychiatry 9: 731-734.

Mitra R, Adamec R, Sapolsky R (2009). Resilience against predator stress and dendritic morphology of amygdala neurons. Behav Brain Res 205: 535-543.

Mozhui K, Karlsson RM, Kash TL, Ihne J, Norcross M, Patel S et al (2010). Strain differences in stress responsivity are associated with divergent amygdala gene expression and glutamatemediated neuronal excitability. J Neurosci 30: 5357-5367.

Nader K, Majidishad P, Amorapanth P, LeDoux JE (2001). Damage to the lateral and central, but not other, amygdaloid nuclei prevents the acquisition of auditory fear conditioning. Learn Mem 8: 156-163.

Nelson EC, Agrawal A, Pergadia ML, Lynskey MT, Todorov AA, Wang JC et al (2009). Association of childhood trauma exposure and GABRA2 polymorphisms with risk of posttraumatic stress disorder in adults. Mol Psychiatry 14: 234-235.

Onishi BK, Xavier GF (2010). Contextual, but not auditory, fear conditioning is disrupted by neurotoxic selective lesion of the basal nucleus of amygdala in rats. Neurobiol Learn Mem 93: $165-174$.

Ottenweller JE, Natelson BH, Pitman DL, Drastal SD (1989). Adrenocortical and behavioral responses to repeated stressors: toward an animal model of chronic stress and stress-related mental illness. Biol Psychiatry 26: 829-841.

Padival M, Quinette D, Rosenkranz JA (2013a). Effects of repeated stress on excitatory drive of basal amygdala neurons in vivo. Neuropsychopharmacology 38: 1748-1762.

Padival MA, Blume SR, Rosenkranz JA (2013b). Repeated restraint stress exerts different impact on structure of neurons in the lateral and basal nuclei of the amygdala. Neuroscience 246: 230-242. 
Pedarzani P, Krause M, Haug T, Storm JF, Stuhmer W (1998). Modulation of the $\mathrm{Ca} 2+$-activated $\mathrm{K}+$ current sIAHP by a phosphatase-kinase balance under basal conditions in rat CA1 pyramidal neurons. J Neurophysiol 79: 3252-3256.

Pedarzani P, Storm JF (1995). Protein kinase A-independent modulation of ion channels in the brain by cyclic AMP. Proc Natl Acad Sci USA 92: 11716-11720.

Pillai AG, de Jong D, Kanatsou S, Krugers H, Knapman A, Heinzmann JM et al (2012). Dendritic morphology of hippocampal and amygdalar neurons in adolescent mice is resilient to genetic differences in stress reactivity. PLoS One 7: e38971.

Pohl J, Olmstead MC, Wynne-Edwards KE, Harkness K, Menard JL (2007). Repeated exposure to stress across the childhood-adolescent period alters rats' anxiety- and depression-like behaviors in adulthood: the importance of stressor type and gender. Behav Neurosci 121: 462-474.

Power JM, Bocklisch C, Curby P, Sah P (2011). Location and function of the slow afterhyperpolarization channels in the basolateral amygdala. J Neurosci 31: 526-537.

Power JM, Sah P (2008). Competition between calcium-activated $\mathrm{K}+$ channels determines cholinergic action on firing properties of basolateral amygdala projection neurons. J Neurosci 28: 3209-3220.

Rainnie DG, Asprodini EK, Shinnick-Gallagher P (1993). Intracellular recordings from morphologically identified neurons of the basolateral amygdala. J Neurophysiol 69: 1350-1362.

Rainnie DG, Bergeron R, Sajdyk TJ, Patil M, Gehlert DR, Shekhar A (2004). Corticotrophin releasing factor-induced synaptic plasticity in the amygdala translates stress into emotional disorders. J Neurosci 24: 3471-3479.

Rainnie DG, Fernhout BJ, Shinnick-Gallagher P (1992). Differential actions of corticotropin releasing factor on basolateral and central amygdaloid neurones, in vitro. J Pharmacol Exp Ther 263: 846-858.

Razzoli M, Carboni L, Andreoli M, Ballottari A, Arban R (2011). Different susceptibility to social defeat stress of BalbC and C57BL6/J mice. Behav Brain Res 216: 100-108.

Ren Y, Barnwell LF, Alexander JC, Lubin FD, Adelman JP, Pfaffinger PJ et al (2006). Regulation of surface localization of the small conductance $\mathrm{Ca} 2+$-activated potassium channel, Sk2, through direct phosphorylation by cAMP-dependent protein kinase. J Biol Chem 281: 11769-11779.

Rijsdijk FV, Snieder H, Ormel J, Sham P, Goldberg DP, Spector TD (2003). Genetic and environmental influences on psychological distress in the population: General Health Questionnaire analyses in UK twins. Psychol Med 33: 793-801.

Rodrigues SM, Schafe GE, LeDoux JE (2001). Intra-amygdala blockade of the NR2B subunit of the NMDA receptor disrupts the acquisition but not the expression of fear conditioning. J Neurosci 21: 6889-6896.

Rodriguez Manzanares PA, Isoardi NA, Carrer HF, Molina VA (2005). Previous stress facilitates fear memory, attenuates GABAergic inhibition, and increases synaptic plasticity in the rat basolateral amygdala. J Neurosci 25: 8725-8734.

Rogers J, Raveendran M, Fawcett GL, Fox AS, Shelton SE, Oler JA et al (2013). CRHR1 genotypes, neural circuits and the diathesis for anxiety and depression. Mol Psychiatry 18: 700-707.

Romeo RD, Karatsoreos IN, McEwen BS (2006). Pubertal maturation and time of day differentially affect behavioral and neuroendocrine responses following an acute stressor. Horm Behav 50: 463-468.

Rosenkranz JA, Venheim ER, Padival M (2010). Chronic stress causes amygdala hyperexcitability in rodents. Biol Psychiatry 67: $1128-1136$.

Rutter M (1985). Resilience in the face of adversity. Protective factors and resistance to psychiatric disorder. $\mathrm{Br} J$ Psychiatry 147: 598-611.
Sandi C, Cordero MI, Ugolini A, Varea E, Caberlotto L, Large CH (2008). Chronic stress-induced alterations in amygdala responsiveness and behavior-modulation by trait anxiety and corticotropin-releasing factor systems. Eur J Neurosci 28: 1836-1848.

Sapolsky RM, Meaney MJ (1986). Maturation of the adrenocortical stress response: neuroendocrine control mechanisms and the stress hyporesponsive period. Brain Res 396: 64-76.

Sarapas C, Cai G, Bierer LM, Golier JA, Galea S, Ising M et al (2011). Genetic markers for PTSD risk and resilience among survivors of the World Trade Center attacks. Dis Markers 30: 101-110.

Savignac HM, Hyland NP, Dinan TG, Cryan JF (2011). The effects of repeated social interaction stress on behavioural and physiological parameters in a stress-sensitive mouse strain. Behav Brain Res 216: 576-584.

Schmidt MV, Trumbach D, Weber P, Wagner K, Scharf SH, Liebl C et al (2010). Individual stress vulnerability is predicted by short-term memory and AMPA receptor subunit ratio in the hippocampus. J Neurosci 30: 16949-16958.

Segman RH, Cooper-Kazaz R, Macciardi F, Goltser T, Halfon Y, Dobroborski $\mathrm{T}$ et al (2002). Association between the dopamine transporter gene and posttraumatic stress disorder. $\mathrm{Mol}$ Psychiatry 7: 903-907.

Selye H (1936). A syndrome produced by diverse nocuous agents. Nature 138: 32.

Smolka MN, Schumann G, Wrase J, Grusser SM, Flor H, Mann K et al (2005). Catechol-O-methyltransferase val158met genotype affects processing of emotional stimuli in the amygdala and prefrontal cortex. J Neurosci 25: 836-842.

Southwick SM, Vythilingam M, Charney DS (2005). The psychobiology of depression and resilience to stress: implications for prevention and treatment. Annu Rev Clin Psychol 1: 255-291.

Spear LP (2000). The adolescent brain and age-related behavioral manifestations. Neurosci Biobehav Rev 24: 417-463.

Stein MB, Campbell-Sills L, Gelernter J (2009). Genetic variation in 5HTTLPR is associated with emotional resilience. Am J Med Genet B Neuropsychiatr Genet 150B: 900-906.

Stiller AL, Drugan RC, Hazi A, Kent SP (2011). Stress resilience and vulnerability: the association with rearing conditions, endocrine function, immunology, and anxious behavior. Psychoneuroendocrinology 36: 1383-1395.

Stone EA, Quartermain D (1997). Greater behavioral effects of stress in immature as compared to mature male mice. Physiol Behav 63: 143-145.

Taliaz D, Loya A, Gersner R, Haramati S, Chen A, Zangen A (2011). Resilience to chronic stress is mediated by hippocampal brain-derived neurotrophic factor. J Neurosci 31: 4475-4483.

Teicher MH, Andersen SL, Polcari A, Anderson CM, Navalta CP, Kim DM (2003). The neurobiological consequences of early stress and childhood maltreatment. Neurosci Biobehav Rev 27: 33-44.

Toledo-Rodriguez M, Sandi C (2007). Stress before puberty exerts a sex- and age-related impact on auditory and contextual fear conditioning in the rat. Neural Plast 2007: 71203.

Treiman DM, Levine S (1969). Plasma corticosteroid response to stress in four species of wild mice. Endocrinology 84: 676-680.

Ulrich-Lai YM, Figueiredo HF, Ostrander MM, Choi DC, Engeland WC, Herman JP (2006). Chronic stress induces adrenal hyperplasia and hypertrophy in a subregion-specific manner. Am J Physiol Endocrinol Metab 291: E965-E973.

Vidal J, Bie J, Granneman RA, Wallinga AE, Koolhaas JM, Buwalda $B$ (2007). Social stress during adolescence in Wistar rats induces social anxiety in adulthood without affecting brain monoaminergic content and activity. Physiol Behav 92: 824-830.

Volman I, Verhagen L, den Ouden HE, Fernandez G, Rijpkema M, Franke B et al (2013). Reduced serotonin transporter availability decreases prefrontal control of the amygdala. J Neurosci 33: 8974-8979. 
Vyas A, Chattarji S (2004). Modulation of different states of anxiety-like behavior by chronic stress. Behav Neurosci 118: 1450-1454.

Vyas A, Mitra R, Shankaranarayana Rao BS, Chattarji S (2002). Chronic stress induces contrasting patterns of dendritic remodeling in hippocampal and amygdaloid neurons. J Neurosci 22: 6810-6818.

Vyas A, Pillai AG, Chattarji S (2004). Recovery after chronic stress fails to reverse amygdaloid neuronal hypertrophy and enhanced anxiety-like behavior. Neuroscience 128: 667-673.

Wald I, Degnan KA, Gorodetsky E, Charney DS, Fox NA, Fruchter $\mathrm{E}$ et al (2013). Attention to threats and combat-related posttraumatic stress symptoms: prospective associations and moderation by the serotonin transporter gene. JAMA Psychiatry 70: 401-408.

Walker CD, Scribner KA, Cascio CS, Dallman MF (1991). The pituitary-adrenocortical system of neonatal rats is responsive to stress throughout development in a time-dependent and stressor-specific fashion. Endocrinology 128: 1385-1395.

Washburn MS, Moises HC (1992). Electrophysiological and morphological properties of rat basolateral amygdaloid neurons in vitro. J Neurosci 12: 4066-4079.

Weaver IC, Szyf M, Meaney MJ (2002). From maternal care to gene expression: DNA methylation and the maternal programming of stress responses. Endocr Res 28: 699.
Weiss IC, Pryce CR, Jongen-Relo AL, Nanz-Bahr NI, Feldon J (2004). Effect of social isolation on stress-related behavioural and neuroendocrine state in the rat. Behav Brain Res 152: 279-295.

White MG, Bogdan R, Fisher PM, Munoz KE, Williamson DE, Hariri AR (2012). FKBP5 and emotional neglect interact to predict individual differences in amygdala reactivity. Genes Brain Behav 11: 869-878.

Willner P, Moreau JL, Nielsen CK, Papp M, Sluzewska A (1996). Decreased hedonic responsiveness following chronic mild stress is not secondary to loss of body weight. Physiol Behav 60: 129-134.

Wood SK, Walker HE, Valentino RJ, Bhatnagar S (2010). Individual differences in reactivity to social stress predict susceptibility and resilience to a depressive phenotype: role of corticotropin-releasing factor. Endocrinology 151: 1795-1805.

Zhang W, Rosenkranz JA (2012). Repeated restraint stress increases basolateral amygdala neuronal activity in an agedependent manner. Neuroscience 226: 459-474.

Zhang W, Rosenkranz JA (2013). Repeated restraint stress enhances cue-elicited conditioned freezing and impairs acquisition of extinction in an age-dependent manner. Behav Brain Res 248: 12-24.

Zimmerman JM, Maren S (2010). NMDA receptor antagonism in the basolateral but not central amygdala blocks the extinction of Pavlovian fear conditioning in rats. Eur J Neurosci 31 1664-1670.

Supplementary Information accompanies the paper on the Neuropsychopharmacology website (http://www.nature.com/npp) 